\title{
DESPERATELY SEEKING (ENVIRONMENTAL) KUZNETS
}

\author{
Marzio Galeotti \\ University of Bergamo and Fondazione Eni Enrico Mattei \\ and \\ Alessandro Lanza \\ International Energy Agency
}

Abstract. The number of studies seeking to empirically characterize the reduced-form relationship between a country economic growth and the quantity of various pollutants produced has recently increased significantly. In several cases researchers have found evidence in favor of an inverted-U "environmental Kuznets" curve. In the case of a major greenhouse gas, $\mathrm{CO}_{2}$, however, the evidence is at best mixed. This paper attempts to shed further light on this issue by using a newly developed data set covering over one hundred countries around the world for the last twenty five years and by considering alternative functional forms together with an effort to rigorously discriminate among competing alternatives.

First draft: June 1998. Revised: January 1999.

Keywords: Environment, Growth, $\mathrm{CO}_{2}$ Emissions, Panel Data

JEL Classification: O13, Q30, Q32, C12, C23

Paper presented at the 1998 World Congress of Environment and Resource Economists, Venice, 25-27 June. The authors would like to acknowledge helpful comments and opinions offered by Andrea Beltratti, Jean-Marie Bourdaire, Carlo Carraro, Matteo Manera, Michele Pinna, Marcella Pavan, Lee Schipper, Caroline Varley, and especially Michael McAleer. This study does not necessarily reflect the views of the International Energy Agency or any of its member countries.

Corresponding author: Dr. Alessandro Lanza, International Energy Agency, 9 Rue de la Féderation, 75739 Paris, Cedex 15; e-mail: alessandro.lanza@iea.org 


\section{DESPERATELY SEEKING (ENVIRONMENTAL) KUZNETS}

\section{Non-Technical Summary}

The relation between economic development and environmental quality is a very complex issue. For this reason, in the last few years several studies have tried to characterize this problem as an empirical reduced-form relationship. In particular, a few studies have identified a bell shaped curve for the pollution intensity of GDP. This behavior implies that, starting from low (per capita) income levels, (per capita) emissions or concentrations tend to increase but at a slower pace. After a certain level of income, emissions or concentrations start to decline as income further increases. In the case of a major greenhouse gas, $\mathrm{CO}_{2}$, however, the evidence of an inverted- $\mathrm{U}$ "Kuznets curve" is at best mixed.

While all the studies have focused upon the empirical emergence of the environmental Kuznets curve and have typically discussed its implications with special reference to the value of the income turning point, the analysis concerning the robustness of the basic findings has not been, somewhat surprisingly, a major concern. The issue of the functional form for the reduced-form relationship between $\mathrm{CO}_{2}$ emissions and GDP appears to be critical for the emergence of a bell shaped curve and for the crucial policy implications that could be drawn from such an empirical finding.

We argue in this paper that the empirical relationship between a country GDP and $\mathrm{CO}_{2}$ emissions ought to undergo a more careful scrutiny from at least two standpoints. In this paper we start from the observations that nearly all papers in this literature use the same source of data for $\mathrm{CO}_{2}$ emissions and almost invariably fit to the data either linear-in-variables or log-linear functional relationships. Departing from this practice, we estimate the "standard" relationship on a newly developed data set for emissions. We also apply the theory of non-nested hypothesis testing in the attempt to choose between linear and log-linear models. After having noted a few theoretical and empirical drawbacks of these functional specifications, we propose two alternative functional forms, Gamma and Weibull, which are subsequently implemented. The estimated results are satisfactory and the features of the EKC relationship reasonable. Finally, interestingly enough non-nested tests produce the unambiguous result that Gamma and Weibull are to be preferred to the usual log-linear functional form. In summary, the evidence presented in this paper demonstrates that, when alternative new functional forms are employed for describing the reduced-form relationship between $\mathrm{CO}_{2}$ emissions and GDP relative to the standard ones, the emergence of a bell-shaped

Environmental Kuznets Curve with reasonable turning points is a possibility that cannot be discarded. 


\section{Introduction}

The threat of climate change due to global warming is an issue whose relevance is by now recognized by all experts, governments, and public opinions throughout the world. The Earth Summit held in Rio de Janeiro in 1992 and the 1997 Kyoto Summit have called the international attention upon its negative consequences as well as upon the potential instruments to tackle this problem.

One of the most important issues in the policy arena is related to the role that should be played by developing countries. In fact, the industrialized countries agreed in Kyoto upon an overall \%5 reduction in greenhouse gas emissions from 1990 levels over a first commitment period lasting from 2008 to 2012. No such commitment has been taken by developing countries, the usual argument in favor of this position being that the industrialization process should require no constraint particularly for energy production and consumption.

Underlying this position, there is a long-standing debate on the relationship between economic development and environmental quality. From a sustainable development viewpoint there is no doubt that, during the last decade, there has been a growing concern that the economic expansion of the world economy will cause irreparable damage to our planet. That concern stems from two rather intuitive concepts that have received a considerable attention at both research and policy levels (see, for instance, Grossman, 1995): first, more output requires more inputs so that the earth's natural resources (including also exhaustible energy sources) will be quickly depleted (exhaustibility issue); second, more output causes more emissions and waste: the earth could soon exceed the carrying capacity of the biosphere (carrying capacity issue).

A careful analysis of this issue is quite complicated a task and the relationship between economic growth and pollution is very complex, depending upon a host of different factors. Among these are: the size of the economy; the sectoral structure, including the composition of the energy demand; the vintage of the technology; the demand for environmental quality; the level (and quality) of environmental protection expenditures. All these aspects are interrelated. For example, countries with the same sectoral composition of output may have a different level of emissions if their capital stocks are different in terms of technological vintage. 
In the last few years several studies have appeared dealing the relationship between the scale of economic activity and the level of pollution (see the survey articles by Stern, Common, and Barbier, 1996; Barbier, 1997; Ekins, 1997; Mc Connell, 1997; Stern, 1998). In particular, if we concentrate on local pollutants, typically measures of air and water quality, several empirical studies have identified for a number of pollutants a bell shaped curve for the pollution intensity of GDP (Shafik and Bandyopadyay, 1992; Shafik, 1994; Selden and Song, 1994; Grossman, 1995; Grossman and Krueger, 1995; Panayotou, 1997). This behavior implies that, starting from low (per capita) income levels, (per capita) emissions or concentrations tend to increase but at a slower pace. After a certain level of income (which typically differs across pollutants) - the "turning point" - emissions or concentrations start to decline as income further increases. In the 1940s Simon Kuznets empirically identified an inverted-U historic relationship between income distribution and income growth, which was then termed "Kuznets Curve" after him. Given the obvious analogy, the bell shaped relationship between per capita income and pollution has been dubbed "Environmental Kuznets Curve" (EKC hereafter).

It is remarkable that most studies have concentrated on a number of local pollutants, while the analysis of the relationship between income and global emissions, and those of $\mathrm{CO}_{2}$ in particular, has received, at least until recently, much less attention.

Based on economic theory, two main explanations have been put forth to rationalize the EKC relationship. The first is that the Kuznets behavior is an income effect and results from the environment being a luxury good. Early in the economic development process of a country individuals are unwilling to trade consumption for investment in environmental protection: environmental quality declines as a result. Once individuals reach a given level of consumption (or income), they begin to demand increasing investments in an improved environment. Thus, after the "income turning point", environmental quality indicators begin to display reductions in pollution and environmental degradation.

The other common explanation is that the EKC is another expression of the "stages of economic growth" economies go through as they make a transition from agriculture-based to industry and then post-industrial service-based systems (Baldwin, 1995). The transition from an agricultural to an industrial economy results in increasing 
environmental degradation as mass production and consumption grow. The transition from an industrial to a service-based economy is instead assumed to result in decreasing degradation due to the lower environmental impact of service industries. A slightly modified view is the idea that economies pass through technological life cycles, moving from polluting technology to high technology. ${ }^{1}$

The case of global pollutants such as $\mathrm{CO}_{2}$ emissions, however, is rather special in terms of the above explanations. The different policy attitude toward local as opposed global pollutants should be clear. The protection of a global common requires policies aimed at sustaining a global agreement for which free riding behavior is one of the possible outcomes.

The global nature of this pollutant and its crucial role as a major determinant of the greenhouse effect attribute to the analysis of the $\mathrm{CO}_{2}$ emissions-income relationship special interest. This is mainly because the message implicit in a bell shaped EKC is that GDP is both the cause and the cure of the environmental problem. In the case of $\mathrm{CO}_{2}$ emissions this fact has such far-reaching implications that extreme caution and careful scrutiny are necessary when analyzing the issue. A growing number of empirical studies have therefore recently looked for an $\mathrm{EKC}$ in the $\mathrm{CO}_{2}$ emissions case (Shafik and Bandyopadyay, 1992; Holtz-Eakin and Selden, 1995; Tucker, 1995; Cole, Rayner, and Bates, 1997; Moomaw and Unruh, 1997; Roberts and Grimes, 1997; Schmalensee, Stoker, and Judson, 1998). While an exhaustive survey of the results is beyond the scope of this paper, a few aspects shared by nearly all the studies ought to be mentioned:

(i) The relationship considered is a reduced-form equation relating per capita $\mathrm{CO}_{2}$ emissions to per capita income. In general, and with the possible exception of a time trend, no extra explanatory variables are included.

(ii) The analysis is usually conducted on a panel data set of individual countries around the world. Moreover, the data for $\mathrm{CO}_{2}$ emissions almost invariably have come from a single source, namely the Oak Ridge National Laboratory. ${ }^{2}$

\footnotetext{
1 A few theoretical explanations of the EKC in terms of its microfoundations have been very recently proposed (see, for example, Andreoni and Levinson, 1998, and the references therein).

2 The data for real per capita GDP are typically drawn from the Penn World Table and are on a PPP basis.
} 
(iii) The functional relationship considered is either linear or log-linear one, with a few studies considering both (Holtz-Eakin and Selden, 1995; Cole, Rayner, and Bates, 1997). ${ }^{3}$

(iv) Due to the almost complete coverage of world countries, the estimation technique is typically the least square dummy variable method, allowing for both fixed country and time effects. ${ }^{4}$

While all the studies quoted so far have focused upon the empirical emergence of the EKC and have typically discussed its implications with special reference to the level of the income turning point, the analysis concerning the robustness of the basic findings has not been, somewhat surprisingly, a major concern.

The most recent series of contributions in the EKC literature share the common feature of criticizing, from various standpoints, the previous empirical practice and findings. The most recurrent criticism is the omission of relevant explanatory variable in the basic relationship. Thus, besides income and time trend, we ought to include trade because of the so-called "pollution heaven" or "environmental dumping" hypothesis (Hettige, Lucas, and Wheeler, 1992; Kaufmann, Davidsdottir, Garnham, and Pauly, 1998; Suri and Chapman, 1998), energy prices to account for the intensity of use of raw materials (de Bruyn, van den Bergh, and Opschoor, 1998), and a host of other variables if we care about political economy considerations due to the public good nature of the environment (Torras and Boyce, 1998). In addition, allowance should be made for changes in either the sectoral structure of production or the consumption mix (Hettige, Mani, and Wheeler, 1998; Rothman, 1998) or for the distinction, when data permit, between polluting activity and pollution intensity which, when related to GDP, work in opposite directions (Hilton and Levinson, 1998). Finally, a more fundamental criticism is that of "income determinism" of empirical EKCs which implicitly hold that the experience of a country is equal to that of all other (Unruh and Moomaw, 1998).

One important aspect that has undergone close scrutiny in essentially all the papers mentioned so far is the issue of functional forms relating $\mathrm{CO}_{2}$ emissions to GDP.

\footnotetext{
3 Exceptions are Tucker (1995), who considers a quadratic relationship in the first-differenced variables, and Roberts and Grimes (1997), who posit a linear relationship between the $\log$ of $\mathrm{CO}_{2}$ emissions and the log of GDP, but with GDP squared entering in levels.
} 
The only noticeable effort in that direction has been the explicit consideration of a thirdorder, rather than just a second-order polynomial for the linear or log-linear models. Also, as said, only two studies have estimated both linear and log-linear specifications. The issue of the functional form for the reduced-form relationship between $\mathrm{CO}_{2}$ emissions and GDP appears to be critical for the emergence of a "well-behaved" EKC and for the crucial policy implications that could be drawn from such an empirical finding. Indeed, while many researchers warn that a reduced-form relationship is illsuited for drawing policy prescriptions, it cannot be denied that an inverted-U relationship for $\mathrm{CO}_{2}$ emissions intensity suggests that pollution reduction might be expected to occur as a natural by-product of economic development.

We argue in this paper that the empirical relationship between a country GDP and the emissions of a major greenhouse gas, $\mathrm{CO}_{2}$, ought to undergo a more careful examination from at least two standpoints. The first one is to fit the "standard" linear relationship, be that in levels or in logarithms, using an alternative, possibly better, data set. The second one is to study more carefully the shape of the estimated environmental Kuznets relationship together with a rigorous attempt to discriminate among alternative functional forms by statistical means. In so doing, alternative non-linear functional forms may be suggested and contrasted with the usual ones. This is what we do in the present paper.

The structure of this paper is the following. Section 2 discusses the new data set used highlighting advantages and disadvantages relative to existing alternatives. In section 3 we estimate the standard linear and log-linear models and discuss the evidence so obtained. In section 4 we propose and estimate alternative functional forms for the EKC and use the theory on non-nested hypothesis testing to choose the preferred specification. Concluding remarks close the paper.

\section{The Data}

\footnotetext{
4 de Bruyn, van den Bergh, and Opschoor (1998) show how a bell shaped EKC may spuriously obtain as a result of the interplay between time effect and aggregation across countries. Roberts and Grimes (1997) estimate individual cross sections for several years.
} 
Our analysis exploits a data set recently developed by IEA (International Energy Agency, 1997). It covers the period between 1960 to 1995 for the Annex II countries of the United Nations Framework Convention on Climate Change (Rio de Janeiro, 1992) and between 1971 to 1995 for all the other countries. In order to avoid complications related to the use of an unbalanced sample and because the most relevant period for our purposes pertains to the last thirty years, we employ data that cover the 1971 to 1995 period for 108 countries. In 1995 these accounted for $88 \%$ of the $\mathrm{CO}_{2}$ emissions generated by fuel combustion. ${ }^{5}$ The series for Gross Domestic Product (GDP) and population of the OECD countries (with the exception of Czech Republic, Hungary, Poland and the Republic of Korea) come from the OECD Main Economic Indicators. The corresponding series for the other countries have been obtained from the World Bank. $^{6}$

On the whole, the sample consists of 2,700 annual observations. However, in order to account for the different stage of economic development, position relative to the technological frontier, and other structural differences, we have also considered and analyzed the sub-samples of OECD and non-OECD countries. The former includes 28 nations for 700 observations, while the latter includes 80 countries for a total of 2,000 observations.

As mentioned in the Introduction, the only source of data so far used by researchers interested in $\mathrm{EKC}$ analysis for $\mathrm{CO}_{2}$ emissions has been the one made available by the Carbon Dioxide Information Analysis Center (CDIAC) of the Oak Ridge National Laboratory (Marland, Anders, Boden, Johnston, and Brenkert, 1998). CDIAC distributes and updates a specific data set concerning global, regional, and national $\mathrm{CO}_{2}$ emission estimates from fossil fuel burning, cement production, and gas flaring. The data are calculated using energy statistics published annually by the United Nations and using the methods described in Marland and Rotty (1983). Cement production estimates came from the U.S. Department of Interior's Bureau of Mines, while gas-flaring estimates are

\footnotetext{
${ }^{5}$ A few countries have been omitted from the original data set. Kuwait, Luxembourg and Netherlands Antilles were also excluded, being clear outliers in either per capita emissions or per capita GDP dimensions or both (see also, for instance, Holtz-Eakin and Selden, 1995). The complete list of countries included in our dataset is available from the authors.

${ }^{6}$ GDP data for the Czech Republic from 1990 onwards come from the OECD and from 1971 to 1989 are IEA estimates.
} 
derived principally from United Nations energy statistics but supplemented with estimates from the U.S. Department of Energy. The available data are annual and cover the period 1950-1994.

There are several differences between the CDIAC data set and the one used in this paper. The IEA data set is based on energy balances and does not include either cement production or gas flaring. The impact of these emissions is however rather small and they collectively contributed less than $4 \%$ to total emissions in 1995 . The IEA data set appears to be more precise for at least a couple of reasons. Firstly, IEA has a long reputation in collecting energy balances that are the basis for the emissions data sets used by most papers. Secondly, IEA has been able to use specific emission coefficients for different energy products, while in the CDIAC case a single coefficient has been used for gas, oil, and solid fossil fuels without any distinction among individual energy products.

While it is not the purpose of this paper to conduct a detailed analysis of differences between the two data sets, we believe that there are good reasons for studying the EKC issue, its emergence and features, using this alternative, possibly of higher quality, data set. ${ }^{7}$

\section{The Standard Specification: Linear and Log-linear Models}

Basically all the papers in the EKC literature assume that the empirical reduced-form relationship between per capita $\mathrm{CO}_{2}$ emissions and GDP can be adequately described by a parametric model, and specifically by a polynomial function of income. Being linear in parameters, such relationship can be estimated using standard econometric techniques: in particular, country fixed effects with time dummies estimates have been typically presented. ${ }^{8}$ The estimated regression models have often differed in two respects: (i) the equation is either linear or log-linear in the variables; (ii) the equation is either quadratic or cubic. Thus, for instance, Moomaw and Unruh (1997)

\footnotetext{
7 In future work we plan to use the alternative functional forms and apply the statistical approach to model specification testing of this paper to the CDIAC data set, in order to get a more precise assessment of the differences between the two data sets.

8 Holtz-Eakin and Selden (1995) is the only study considering also a random effects specification, although fixed effects appear to be a more appropriate solution given the coverage of the panel. Also, a few studies use a time trend which however describes a more restrictive pattern than time dummies.
} 
consider a linear-in-variables specification with either quadratic or cubic income terms; Holtz-Eakin and Selden (1995) and Cole, Rayner, and Bates (1997) consider the two functional forms for both quadratic and cubic cases. ${ }^{9}$ The two general models look like the following: ${ }^{10}$

$$
\begin{aligned}
& C O 2_{i t}=\alpha_{i}+\alpha_{t}+\alpha_{1} G D P_{i t}+\alpha_{2} G D P_{i t}{ }^{2}+\alpha_{3} G D P_{i t}{ }^{3}+u_{i t} \\
& \log C O 2_{i t}=\beta_{i}+\beta_{t}+\beta_{1} \log G D P_{i t}+\beta_{2}\left(\log G D P_{i t}\right)^{2}+\beta_{3}\left(\log G D P_{i t}\right)^{3}+v_{i t}
\end{aligned}
$$

where $i=1, \ldots N$ indexes countries and $t=1, \ldots T$ indexes time. The terms $\alpha_{i}$ and $\beta_{i}$ represent country fixed effects, $\alpha_{t}$ and $\beta_{t}$ stand for year fixed effects, and $u_{i t}$ and $v_{i t}$ are white noise disturbances. We control for the fixed country and time effects with a set of appropriate dummy variables. For future reference, we note that the fixed effects always enter linearly all the estimated models considered here.

The choice between linear and log-linear models has been the subject of several contributions to the econometric literature (see, for instance, McAleer, 1994). On conceptual grounds the selection of either specification is not without implications: suffice to remember that the first model yields constant marginal effects and variable elasticities, while the second model does precisely the opposite; the log-linear model may appear to some researchers preferable because it yields steady-state growth paths or because it implies multiplicative, rather than additive, individual effects; the linear model is attractive because its computational simplicity, the (almost) immediate interpretability of some of its coefficients, and its temporal aggregability.

For the purpose of studying the possible emergence of an inverted-U environmental Kuznets relationship a few remarks are important. Firstly, the log-linear model imposes non-negativity restrictions upon the variables, which the linear model does not. In the case of a concave relationship, such as perhaps the EKC, the requirement that emissions cannot become negative, albeit at very high income levels, may not be an unreasonable restriction to impose. Secondly, the linear model imposes a

We have considered both alternatives in our empirical work with no appreciable differences in the estimation results.

9 A nonparametric approach is followed by Schmalensee, Stoker, and Judson (1998) who postulate a log-linear model with a spline (piecewise linear) function of income.

${ }^{10} \mathrm{In}$ all the equations of the paper $\mathrm{CO}_{2}$ and GDP are meant in per capita terms. 
symmetric behavior on the estimated relationships, a fact, which appears unwarranted on a priori grounds. This is not so in the log-linear case. Thirdly, when a cubic linear-invariables relationship is fitted to the data, the attractiveness of easily interpretable coefficients is lost. Actually, it can be shown that several cases arise depending on the sign of the parameters $\alpha_{2}$ and $\alpha_{3}$ in (1), from which it clearly emerges that a bell shaped EKC may obtain only under quite special circumstances. From these remarks we conclude that a cubic income term ought to be always included in (1) and its statistical significance considered, no matter the magnitude of the corresponding coefficient. ${ }^{11}$ Indeed, the possibility of obtaining an N-shaped curve, with two turning points and emissions increasing as income goes further up, can not be ruled out. ${ }^{12}$ Finally, in the case of the log-linear specification, because of the non-linear transformation undergone by the model variables, there is no closed form analytical expression for the income turning point and it is not possible to predict a priori the behavior of the function on the basis of the parameter signs, thus limiting their interpretability. ${ }^{13}$

\subsection{Estimation Performance}

With those considerations in mind, following the bulk of the literature, we start by estimating equations (1) and (2). As mentioned in the introduction, the exclusion from those equations of explanatory variables other than GDP is one of the relevant issues taken up by the literature on EKCs and their empirical formulation. In general it is important to distinguish between variables that could be directly related to GDP (and thus could be considered endogenous) and those representing exogenous influences. Persistent differences across countries in fossil fuels demand, shares of different fossil fuels, output mixes, regulatory structures, taxes and subsidies are captured by specific country dummies included in the regression models. In addition, fixed effects reflect changes in technologies or different environmental policies. Finally, time specific dummies are included to reflect changes over time in domestic prices, for which historical data are not always available and other country-invariant effects.

\footnotetext{
${ }^{11}$ In an appendix available from the authors the relationship is studied between curvature and income turning points and the sign of $\alpha_{2}$ and $\alpha_{3}$ in the linear-in-variables specification.

${ }^{12}$ Some authors feel uncomfortable with this result. For instance, Holtz-Eakin and Selden (1995) refer to it as an "unattractive property" and focus their attention on the quadratic model.

${ }^{13}$ See the above mentioned appendix available upon request.
} 
Besides the whole sample in the empirical work we have considered also the sub-samples comprising the OECD and non-OECD countries respectively. This disaggregation is suggested by several reasons, including the different stage in historical economic growth patterns for the two groups of countries, the different prevailing production technologies and consumer tastes.

The results of the estimation using the three samples are presented in Table 1 for the linear-in-variables model and in Table 2 for the log-linear specification. For each sample, two different specifications have been tried, respectively excluding and including a cubic income term. As a general comment, it can be seen that the fit of the equations is always satisfactory when judged according to the adjusted $\mathrm{R}^{2}$, with the log-linear specification performing marginally better especially in the case of the samples of All countries and non-OECD countries. The reported $\mathrm{F}$ tests show the statistical relevance of the country effects as well as that of the time effects, although differences among countries are far more important than changes within countries over time (see also Schmalensee, Stoker, and Judson, 1998, for a similar finding).

Turning to the estimated parameters, and considering the linear-in-variables model first, we immediately note that the cubic term for income is always statistically significant. This is an important piece of information in view of the determination of the shape of the EKC, which calls for a joint examination of the parameters $\alpha_{2}$ and $\alpha_{3}$ in (1). In fact, if we were to limit ourselves to consider the quadratic specification, a bell shaped EKC would clearly be obtained for all samples. In the case of the cubic specification, as shown in Figure 1, the estimated parameters produce a "well behaved" EKC for the All countries and non-OECD countries samples, while in the case of the OECD countries the data produce the unpleasant finding of an N-shaped relationship. ${ }^{14}$

The evidence from the log-linear model is slightly better in terms of econometric performance, but not more encouraging in terms of estimated EKC. Indeed, we again obtain a strongly significant cubic term for (the log of) income, except for the nonOECD countries. The empirical $\mathrm{CO}_{2}$ emissions-GDP relationship is portrayed in Figure 2. It can be seen that an inverted-U shape shows up in all cases, but a strong asymmetry

\footnotetext{
${ }^{14}$ Notice that in the figures of the paper the horizontal axis does not necessarily coincide with zero emissions. By the same token, because of the presence of fixed country and time effects, the scale on the vertical axis is not necessarily realistic.
} 
characterizes the All countries and (even more) the non-OECD countries samples. This also holds true for the quadratic version of the OECD sample. While the turning points are realistic, the very slow descent of the curve following them carries rather unfavorable policy implications.

One of the main concerns in the EKC literature, besides the shape of the curve, is related to the value of the income turning point. Its presence (and level) has been largely disputed: if there is no turning point, but just a linear relationship between economic growth and $\mathrm{CO}_{2}$ emissions, any policy intervention should be in the direction of a decrease of the slope of this line. Technological development, reduction of the energy use of equipment for given level of service are, among others, potential policy tools. As pointed out by Shafik (1994), a major explanation of this possible finding is related to the free rider problem. There are not major local costs associated with carbon dioxide emissions - all costs in terms of climate change are borne by the rest of the world - and the local benefits in the near term are small in most cases.

It turns out that Shafik and Bandyopadyay (1992) and Shafik (1994) find that per capita $\mathrm{CO}_{2}$ emissions increase monotonically with income growth. In contrast, restricting the attention to a quadratic specification, Holtz-Eakin and Selden (1995) generate an out-of-sample income turning point of $\$ 35,428$ per capita (in 1986 prices), suggesting that substantial economic growth would be required before $\mathrm{CO}_{2}$ emissions began to decline: while present, the estimated turning point is disturbingly high. Sengupta (1996) estimates the $\mathrm{CO}_{2} / \mathrm{GDP}$ relationship using a sample of sixteen countries that includes both developed and developing ones. He finds a much lower income turning point of $\$ 8,740$ per capita (in PPP 1985 dollars), but also a tendency to positive emissions elasticities beyond $\$ 15,300$, thus indicating that emissions decline over a midrange of incomes before re-establishing an upward trend with GDP growth. Cole, Rayner, and Bates (1997) estimate quadratic equations both in the levels and in the logarithms of the variables on a sample of seven world regions. The turning points the authors obtain are set at $\$ 62,700$ in the quadratic logs model and at $\$ 25,100$ in the quadratic levels specification (values in 1985 dollars). Moomaw and Unruh (1997) consider a linear-in-variables cubic model obtaining an $\mathrm{N}$-shaped relationship with a first turning point at $\$ 12,813$ and a second one at $\$ 18,133$, implying a very narrow income 
range for $\mathrm{CO}_{2}$ declines. Our own evidence is reported in the last row of Tables 1 and 2: especially in the case of the linear model, it can be seen that the values of the estimated turning points appear to be reasonable a priori and well within the range of the figures put forth by the aforementioned studies. The relevant exceptions are found in the case of the linear model for the OECD countries sample and the log-linear non-OECD countries regression. ${ }^{15}$

\subsection{Model Selection and Specification Testing}

Summarizing the evidence reached so far, both the linear and log-linear models appear to fit the data reasonably well. The evidence in terms of curvature of the EKC relationship and of the associated turning points is a bit problematic, however. Indeed, on the one hand, the linear model returns a bell-shaped curve, with one relevant exception, but cannot prevent emissions from becoming negative at high income levels; on the other hand, the log-linear model generates undesirable shapes for the EKC. More generally, in view of the important analytical and empirical differences between the two specifications, it appears remarkable that the EKC literature has not made any efforts in the attempt to discriminate rigorously between linear and log-linear models. At the same time, as computational difficulties can nowadays no longer be invoked, other possibly more appealing functional forms for modeling the $\mathrm{CO}_{2}$ emissions intensity can be entertained.

While this issue is postponed until the next section, here we tackle the statistical discrimination between linear and log-linear models, a topic which has traditionally attracted the interested of both econometricians and applied economists, particularly from the viewpoint of non-nested hypothesis testing (see, among others, Godfrey and Wickens, 1981; Davidson and MacKinnon, 1985; Godfrey, McAleer, and McKenzie, 1988). Not only are the two specifications separate from one another, but unlike standard non-nested models, they also entail a known transformation of the dependent variable. This fact calls for the derivation of special tests. Among various possibilities, we have selected three representative examples: the PE (i.e. extended projection) test proposed by MacKinnon, White, and Davidson (1983), the BM test suggested by Bera

\footnotetext{
${ }^{15}$ Other authors have found evidence of an N-shaped curve when analyzing various environmental quality indicators such as solid waste volumes and heavy metal concentrations in river water (Grossman and Krueger, 1995). See Ekins (1997) for a survey of these findings.
} 
and McAleer (1989), and the GW test of Godfrey and Wickens (1981). All these tests are asymptotically valid, the first are based on the principle of artificial regression, while the third is based on the well-known Box-Cox transformation. ${ }^{16}$ The outcome of these tests contrasting the estimated linear and the log-linear models (and vice versa) is presented in Table 3. Unfortunately, as it often happens in non-nested hypothesis testing, both specifications appear to rejected each other, although more strongly so for the linear model. ${ }^{17}$ While it has been documented that these non-nested tests tend to over-reject the null hypothesis in small samples (Godfrey, McAleer, and McKenzie, 1988), it has been noted that these procedures are really designed for testing model specification, not for choosing among competing models. We can however try to corroborate the above findings using an alternative strategy. One early proposal to provide a criterion for the choice among the two separate regression structures was put forth by Box and Cox (1964) (see also Sargan, 1964) and entailed a comparison between the residual sum of squares of the two models after having expressed the dependent variables in similar units. The preferred model is the one with the smallest unexplained variation. In addition, it is possible to construct a test of the null hypothesis that linear and log-linear models are observationally equivalent. If we compare the "corrected" sum of squared residuals of the linear models of Table 1 with the corresponding indicator for the log-linear models of Table 2, it clearly appears that the latter specification is strongly favored (see also Table 7). The test of observational equivalence ( $\mathrm{BC}$ test) reported in Table 3 confirms this result. We can thus conclude that a rigorous examination of the relative performance of linear versus log-linear $\mathrm{CO}_{2}$ emission-GDP relationship tends to privilege the latter.

\section{Alternative Functional Forms}

The difficulties which nevertheless remain with the log-linear specification, both from an analytical standpoint and in terms of empirical performance, have prompted us

\footnotetext{
${ }^{16}$ The non-nested tests used in this paper are briefly reviewed in an appendix available from the authors upon request.

${ }^{17}$ More precisely, each model is rejected against a general comprehensive model. In this sense, these are test in regression direction. Also, from Table 4 it emerges that PE and GW test rejects relatively more strongly the linear model, while the BM test does the opposite except for the OECD countries sample. There are two unambiguous outcomes, both for the cubic specification: one from the BM test for the All countries sample and the other from the GW test from the OECD countries sample.
} 
to search for alternative functional forms which were more desirable from the vantage point of (some or all) the following criteria: (i) to easily interpret the function parameters; (ii) not to restrain a priori the range of possible shapes which can characterize the relationship under study; (iii) to obtain analytical closed-for expressions for the income turning point, so as not to be data dependent; (iv) (i) to perform better econometrically; and (v) to outperform the log-linear specification on statistical testing grounds.

Consider the following non-linear functional forms:

$$
\begin{aligned}
& y=\frac{1}{\beta \Gamma(\alpha)}\left(\frac{x-\gamma}{\beta}\right)^{\alpha-1} \exp \left[-\left(\frac{x-\gamma}{\beta}\right)\right] \\
& y=\frac{\alpha}{\beta}\left(\frac{x-\gamma}{\beta}\right)^{\alpha-1} \exp \left[-\left(\frac{x-\gamma}{\beta}\right)^{\alpha}\right]
\end{aligned}
$$

In the statistical literature expressions (3) and (4) are know as three-parameter Gamma and Weibull functions. They have also been used in applied environmental and ecological economics (Bai, Jakeman, and McAleer, 1992) and are widely employed in duration models (Florens, Fougère, and Mouchart, 1996). One advantage of these functional relationships is the interpretability of the parameters: in fact, $\alpha, \beta$, and $\gamma$ are associated with "shape", "scale", and "shift" of the function: depending upon the values they take on, the relationship can assume a variety of different behaviors. In particular, the scale parameter $\beta$ can be directly related with the height of the function, and therefore with the amount of emissions at which the turning point, if it exists, occurs. The shift or location parameter $\gamma$ controls the position of the function along the horizontal axis, and can thus be traced to the value of the income turning point. ${ }^{18}$ Finally, the most crucial parameter is the shape parameter $\alpha$, which governs the shape of the function. In this respect, in Figures 3 and 4 we have plotted a few theoretical curves for arbitrary different values of

\footnotetext{
${ }^{18}$ The two-parameter version of these function, which is also a popular functional specification, obtains when $\gamma=0$. In the above expressions both scale and shape parameters are expected to be positive and $\gamma$ is less than the minimum observed sample value.
} 
the corresponding parameters. It can be seen that, besides more or less asymmetric inverted-U shapes, the curve can even be exponentially decreasing. Specifically, Gamma and Weibull distributions are similar to the exponential distribution when $\alpha=1$, reverse "J" shaped when $\alpha<1$, and bell shaped when $\alpha>1$. From the inspection of the graphs, it also emerges that the requirement that emissions can not get negative is implicitly imposed. A further valuable aspect of the functional forms proposed here is that they admit an analytical closed form expression for the turning point. In fact, taking the derivative of $y$ in (1) and (2) with respect to $x$, setting it equal to zero and solving for $x$ yields the "turning point" $x^{T P}$ as follows:

$$
\begin{aligned}
& y^{T P}=\gamma+\beta(\alpha-1) \\
& y^{T P}=\gamma+\beta\left(\frac{\alpha-1}{\alpha}\right)^{1 / \alpha}+\gamma
\end{aligned}
$$

From these expression the role played by the function parameters clearly emerges.

\subsection{Estimation Performance}

For our three samples we have estimated (3) and (4) after introducing multiplicative fixed effects and taking $\operatorname{logs}$, so that the regression models become: ${ }^{19}$

$$
\begin{aligned}
& \log C O 2_{i t}=\varphi_{i}+\varphi_{t}+(\alpha-1) \log \left(\frac{G D P_{i t}-\gamma}{\beta}\right)-\left(\frac{G D P_{i t}-\gamma}{\beta}\right)+\varepsilon_{i t} \\
& \log C O 2_{i t}=\psi_{i}+\psi_{t}+(\alpha-1) \log \left(\frac{G D P_{i t}-\gamma}{\beta}\right)-\left(\frac{G D P_{i t}-\gamma}{\beta}\right)^{\alpha}+\omega_{i t}
\end{aligned}
$$

The results of the estimation of models (7) and (8) are presented in Table 4. The fit is satisfactory in all cases, and the parameters are always strongly significant with the 
exception of $\gamma$ in the OECD countries sample for the Weibull functional form. While it is difficult to judge the relative merits of the two specifications on the basis of this evidence alone, we note that the parameters are not stable across samples (this was often the case also for the previous specifications). If we look at Figure 5, which portrays the aspect that the two functions assume on the basis of our data and empirical results, we see that all the estimated relationships display a bell shaped curve. On this basis we are led to conclude that a "well-behaved" EKC is supported by our data. Interestingly, the curves appear to be strongly asymmetrical with a steep increase at low income levels and a slow decline afterwards. The reduction in emissions appears however to be faster for OECD than non-OECD countries. The turning points occur at quite reasonable values, with figures that are higher in the case of non-OECD than of OECD countries. The values of the turning point are also reported in Table 4: a comparison with those of the log-linear model (Table 2) shows that they are generally lower, and therefore presumably more reasonable. These facts could have relevant policy implications. Finally, the figure effectively shows the differences between Gamma and Weibull estimated specifications.

\subsection{Model Selection and Specification Testing}

Do the Gamma and Weibull specifications proposed here as better functional relationship for describing the $\mathrm{CO}_{2}$ emission intensity outperform the widely employed log-linear model? Table 5 provides the answer on the basis of non-nested hypothesis tests. Here, even if the dependent variable is the same across models, specific tests must be used that account for the non-linear nature of Gamma and Weibull specifications. The P (i.e. prediction) test proposed by Davidson and MacKinnon (1981) serves our purposes. It is remarkable that, according to the evidence in the table, the $\mathrm{P}$ test yields an unambiguous outcome in that the log-linear model is rejected by both Gamma and Weibull functional forms. ${ }^{20}$ The BC test of observational equivalence between models confirms this evidence except for the non-OECD. The table also suggests that the data do not allow us to discriminate clearly between Gamma and Weibull functional forms: in

\footnotetext{
${ }^{19}$ Note that the constant terms corresponding to (3) and (4) are absorbed into the coefficients of the fixed effects.

${ }^{20}$ An exception to this statement is the outcome of the Gamma versus log-linear test for the All countries where both models reject each other and for the OECD countries/quadratic case where the
} 
fact, according to the non-nested $\mathrm{P}$ test, in the All countries sample the Gamma is unambiguously the preferred model, whereas in the non-OECD sample (OECD sample) both specifications cannot be rejected (are rejected) against a more general alternative; according to the $\mathrm{BC}$ test, instead, the two functional forms are observationally equivalent in all cases except for the OECD sample where the Weibull is clearly the preferred specification.

The above were all test based on paired comparisons between functional forms. However, as is well known, a more correct procedure would be to conduct multiple comparison non-nested tests when in presence of more than two alternatives (see, for instance, Smith and Smyth, 1990). In Table 6 we have therefore straightforwardly generalized the $\mathrm{P}$ test. It appears that each specification is rejected relatively to the other two, but again this is more strongly so for the log-linear model. Actually, in the case of the All countries sample the Weibull structure cannot be rejected against the other, albeit at the $1 \%$ significance level.

If we really have to choose a functional form to describe the empirical relationship between $\mathrm{CO}_{2}$ emissions and GDP, we can either look at the residual sum of squares of the estimated models or at their maximized log-likelihood. ${ }^{21}$ In this case the evidence from Table 7 would suggest choosing the Weibull functional from, except for the OECD countries sample, where the log-linear model is preferred.

\section{Conclusions}

The empirical research on the link that appears to exist between emissions of a major greenhouse gas and the degree of economic development of a country has been recently spurred by the renewed attention of scientists, policy-makers, and public opinion to the issue of climate change. The reduced-form relationship between per capita $\mathrm{CO}_{2}$ emissions and per capita GDP is known as the Environmental Kuznets Curve and in a few studies it has conveniently displayed a bell shape. If supported by the data, this

log-linear specification prevails. However, this evidence does not hold when the Weibull structure is contrasted with the log-linear one.

${ }^{21}$ These criteria are appropriate for the functional forms at hand, given that they are characterized by the same number of estimated parameters. However, it is to be stressed that selection criteria, while handy, are based on procedures for which the associated statistical significance is unknown. 
finding implies that emissions ought to "naturally" diminish as a country becomes richer and richer. Moreover, identifying the "turning point" would allow the observer of a country to precisely know where his/her country is located along the curve. There is econometric evidence, however, which does not find an inverted-U EKC, but rather, a more problematic $\mathrm{N}$-shaped curve.

In this paper we have started from the observations that nearly all papers in the EKC literature use the same source of data for $\mathrm{CO}_{2}$ emissions and almost invariably fit to the data either linear-in-variables or log-linear functional relationships. Departing from this practice, we have estimated the "standard" relationship on a newly developed data set for emissions. We have also applied the theory of non-nested hypothesis testing in the attempt to choose between linear and log-linear models. After having noted a few theoretical and empirical drawbacks of these functional specifications, we have proposed two alternative functional forms, Gamma and Weibull, which have been subsequently implemented. The estimated results are satisfactory and the features of the EKC relationship reasonable. Non-nested tests have produced the result that essentially Gamma and Weibull are to be preferred to the usual log-linear functional form.

An obvious alternative to the approach followed in this paper, which has investigated the robustness (loosely defined) of traditional functional forms in the EKC literature, was to use a statistical non parametric approach (see Yatchew, 1998). While this is a topic that comes next in our research agenda, we feel that there was a gap in empirical EKC analysis that we hope our paper has contributed to fill.

In summary, the evidence here presented demonstrates that, when alternative new functional forms are employed for describing the reduced-form relationship between $\mathrm{CO}_{2}$ emissions and GDP relative to the standard ones, the emergence of a bell-shaped Environmetal Kuznets Curve with reasonable turning points is a possibility that cannot be discarded. 


\section{References}

ANDREONI, J. And A. LEVINSON (1998), "The Simple Analytics of the Environmental Kuznets Curve", National Bureau of Economic Research Working Paper No.6739.

BAI, J., A.J. JAKEMAN, and M. McALEER (1992), "Estimation and Discrimination of Alternative Air Pollution Models", Ecological Modeling, 64, 89-124.

BALDWIN, R. (1995), "Does Sustainability Require Growth?", in I.Goldin and L.A.Winters (eds.), The Economics of Sustainable Development, Paris: OECD, $51-78$.

BARBIER, E.B. (1997), "Introduction to the Environmental Kuznets Curve Special Issue", Environment and Development Economics, Vol.2, Part 4, 369-382.

BERA, A.K. and M. McALEER (1989), "Nested and Non-nested Procedures for Testing Linear and Log-linear Regression Models", Sankhya, B, 51, 221-224.

BOX, G. and D. COX (1964), "An Analysis of Transformations", Journal of the Royal Statistical Society, Series B, 211-264.

COLE, M.A., A.J.RAYNER, and J.M.BATES (1997), "The Environmental Kuznets Curve: An Empirical Analysis", Environment and Development Economics, Vol.2, Part 4, 401-416.

DAVIDSON, R. and J.G. MacKINNON (1981), "Several Tests for Model Specification in the Presence of Alternative Hypotheses", Econometrica, 49, 781-793.

DAVIDSON, R. and J.G. MacKINNON (1985), "Testing Linear and Loglinear Regressions Against Box-Cox Alternatives", Canadian Journal of Economics, XVIII, 499-517.

de BRUYN, S.M., J.C.J.M. van den BERGH, and J.B. OPSCHOOR (1998), "Economic Growth and Emissions: Reconsidering the Empirical Basis of Environmental Kuznets Curves", Ecological Economics, 25, 161-175.

EKINS, P. (1997), The Kuznets Curve for the Environment and Economic Growth: Examining the Evidence", Environment and Planning A, 29, 805-830.

FLORENS, J.P., D. FOUGERE, and M. MOUCHART (1996), "Duration Models", in L.Mátyás and P.Sevestre eds., The Econometrics of Panel Data, Dordrecht: Kluwer, 491-536.

GODFREY, L.G. and M.R. WICKENS (1981), "Testing Linear and Log-linear Regressions for Functional Form", Review of Economic Studies, 48, 487-496. 
GODFREY, L.G., M. McALEER, and C.R. McKENZIE (1988), "Variable Addition and Lagrange Multiplier Tests for Linear and Logarithmic Regression Models", Review of Economics and Statistics, LXX, 492-503.

GROSSMAN, G. (1995), "Pollution and Growth", in I.Goldin and L.A.Winters (eds.), The Economics of Sustainable Development, Paris: OECD, 19-46.

GROSSMAN, G. and A.B. KRUEGER (1995), "Economic Growth and the Environment", Quarterly Journal of Economics, 112, 353-377.

HETTIGE, H., R.E. LUCAS, and D.WHEELER (1992), "The Toxic Intensity of Industrial Production: Global Patterns, Trends, and Trade Policy", American Economic Review Papers and Proceedings, 82, 478-481.

HETTIGE, H., M. MANI, and D.WHEELER (1998), "Industrial Pollution in Economic Development: Kuznets Revisited", The World Bank, Environmentally Sustainable Development Policy Research Working Paper No.1876.

HILTON, F.G. and A. LEVINSON (1998), "Factoring the Environmental Kuznets Curve: Evidence from Automotive Lead Emissions", Journal of Environmental Economics and Management, 35, 126-141.

HOLTZ-EAKIN, D. and T.M. SELDEN (1995), "Stoking the Fires? $\mathrm{CO}_{2}$ Emissions and Economic Growth", Journal of Public Economics, 57, 85-101.

INTERNATIONAL ENERGY AGENCY (1997), “ $\mathrm{CO}_{2}$ Emissions from Fuel Combustion, A New Basis for Comparing Emissions of a Major Greenhouse Gas", Paris.

KAUFMANN, R.K., B. DAVIDSDOTTIR, S. GARNHAM, and P. PAULY (1998), "The Determinants of Atmospheric $\mathrm{SO}_{2}$ Concentrations: Reconsidering the Environmental Kuznets Curve", Ecological Economics, 25, 209-220.

MacKINNON, J.G., H. WHITE, and DAVIDSON, R. (1983), "Tests for Model Specification in the Presence of Alternative Hypotheses: Some Further Results", Journal of Econometrics, 21, 53-70.

MARLAND, G. and R. M. ROTTY (1983), "Carbon Dioxide Emissions from Fossil Fuels: A Procedure for Estimation and Results for 1950-1981”, DOE/NBB0036, TR003, U. S. Department of Energy, Washington D.C.

MARLAND, G., R.J. ANDRES, T.A. BODEN, C. JOHNSTON, and A. BRENKERT (1998), "Global, Regional, and National $\mathrm{CO}_{2}$ Emission Estimates from Fossil Fuel Burning, Cement Production, and Gas Flaring: 1751-1995", Carbon Dioxide Information Analysis Center, Oak Ridge National Laboratory, Oak Ridge, Tennessee, Report No. ORNL/CDICA-30. 
McALEER, M. (1994), "Sherlock Holmes and the Search for Truth: A Diagnostic Tale", Journal of Economic Surveys, 8, 317-353.

McCONNELL, K.E. (1997), "Income and the Demand for Environmental Quality", Environment and Development Economics, Vol.2, Part 4, 383-400.

MOOMAW, W.R. and G.C.UNRUH (1997), "Are Environmental Kuznets Curves Misleading Us? The Case of $\mathrm{CO}_{2}$ Emissions", Environment and Development Economics, Vol.2, Part 4, 451-464.

PANAYOTOU, T. (1997), "Demystifying the Environmental Kuznets Curve: Turning a Black Box into a Policy Tool", Environment and Development Economics, Vol.2, Part 4, 465-484.

ROBERTS, J.T. and P.E.GRIMES (1997), "Carbon Intensity and Economic Development 1962-91: A Brief Exploration of the Environmental Kuznets Curve", World Development, 25, 191-198.

ROTHMAN, D.S. (1998), "Environmental Kuznets Curves - Real Progress or Passing the Buck? A Case for Consumption-Based Approaches", Ecological Economics, 25, 177-194.

SARGAN, J.D. (1964), "Wages and Prices in the United Kingdom: A Study in Ecnometric Methodology", in P.E.Hart, G.Mills, and J.Whitaker (eds.), Econometric Analysis for National Economic Planning, London: Butterworth \& Co., 25-54.

SCHMALENSEE, R., T.M. STOKER, and R.A. JUDSON (1998), "World Carbon Dioxide Emissions: 1950-2050", Review of Economics and Statistics, LXXX, $15-27$.

SELDEN, T.M. and D.SONG (1994), "Environmental Quality and Development: Is There a Kuznets Curve for Air Pollution Emissions", Journal of Environmental Economics and Management, 27, 147-162.

SENGUPTA, R. (1996), " $\mathrm{CO}_{2}$ Emission-Income Relationship: Policy Approach for Climate Control”, Pacific and Asian Journal of Energy, 7, 207-229.

SHAFIK, N. (1994), "Economic Development and Environmental Quality: An Econometric Analysis", Oxford Economic Papers, 46, 757-773.

SHAFIK, N. AND S. BANDYOPADYAY (1992), "Economic Growth and Environmental Quality", Background Paper for the 1992 World Development Report, The World Bank, Washington D.C.. 
SMITH, M.A. and D.J. SMYTH (1990), "Choosing Among Multiple Nonlinear Nonnested Regression Models with Different Dependent Variables", Economics Letters, 34, 147-150.

STERN, D.I. (1998), "Progress on the Environmental Kuznets Curve?", Environment and Development Economics, 3, 173-196.

STERN, D.I., M.S. COMMON, and E.B. BARBIER (1996), "Economic Growth and Environmental Degradation: The Environmental Kuznets Curve and Sustainable Development", World Development, 24, 1151-1160.

SURI, V. and D. CHAPMAN (1998), "Economic Growth, Trade, and Energy: Implications for the Environmental Kuznets Curve", Ecological Economics, 25, 195-208.

TORRAS, M. and J.K. BOYCE (1998), "Income, Inequality, and Pollution: A Reassessment of the Environmental Kuznets Curve", Ecological Economics, 25, 147-160.

TUCKER, M. (1995), “Carbon Dioxide Emissions and Global GDP”, Ecological Economics, 15, 215-223.

UNRUH, G.C. and W.R. MOOMAW (1998), "An Alternative Analysis of apparent EKC-type Transitions”, Ecological Economics, 25, 221-229.

VINCENT, J.R. (1997), "Testing for Environmental Kuznets Curves within a Developing Country", Environment and Development Economics, Vol.2, Part 4, 417-432.

YATCHEW, A. (1998), "Nonparametric Regression Techniques in Economics”, Journal of Economic Literature, XXXVI, 669-721. 


\section{Table 1: Carbon Dioxide Emissions - GDP Relationship Linear Functional Form}

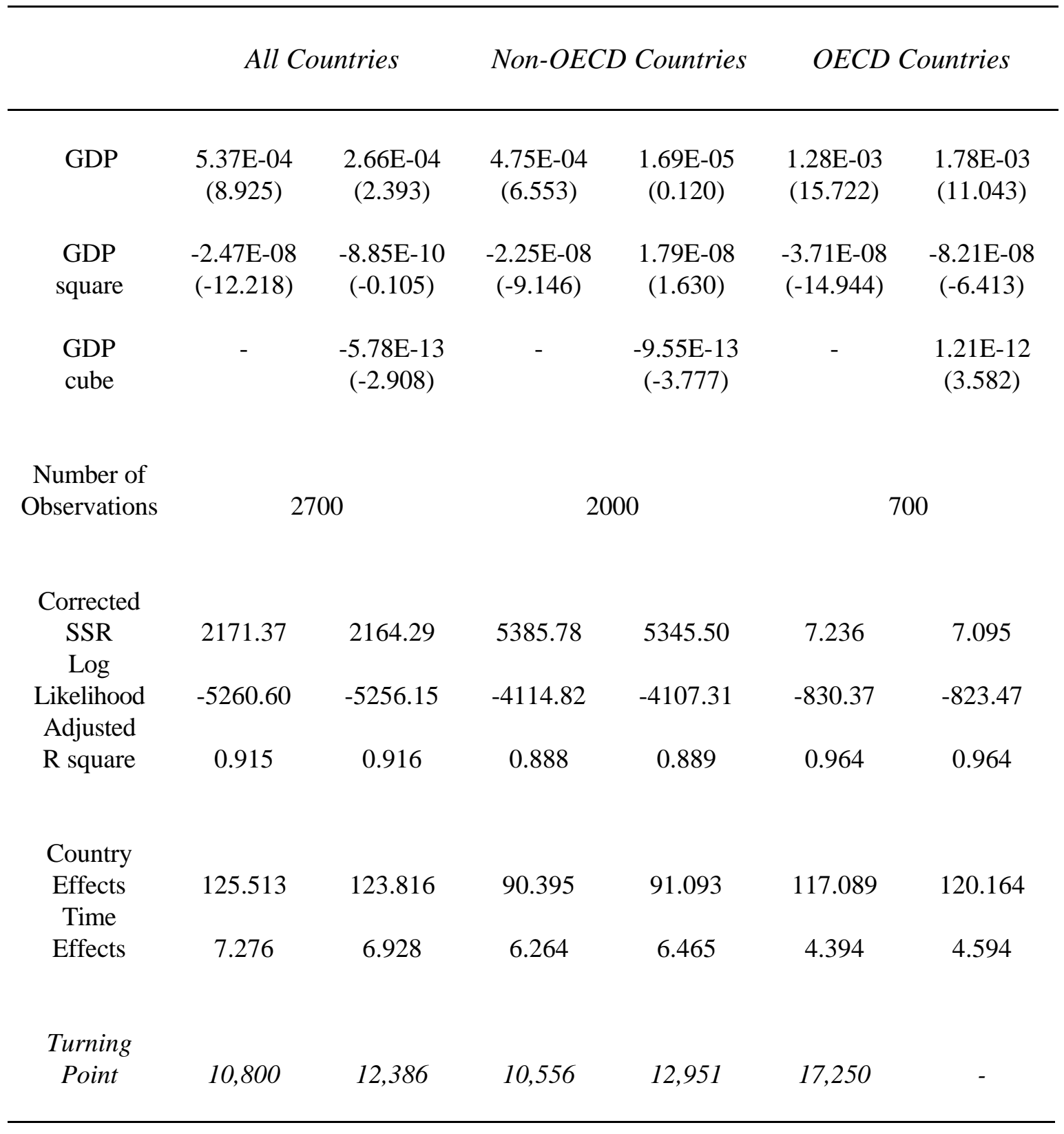

Footnotes:

(1) Dependent variable: carbon dioxide emissions per capita; independent variable: GDP per capita. Estimated coefficients of country and time effects not reported.

(2) T-statistics in parenthesis.

(3) The corrected SSR is the sum of squared residuals divided by the geometric mean of the dependent variable over the sample period.

(4) The turning point is expressed in PPP 1990 U.S. dollars.

(5) Country and fixed effects are F-tests of their absence.

(6) The income turning point is computed analytically. 


\section{Table 2: Carbon Dioxide Emissions - GDP Relationship Log-linear Functional Form}

\begin{tabular}{|c|c|c|c|c|c|c|}
\hline & \multicolumn{2}{|c|}{ All Countries } & \multicolumn{2}{|c|}{ Non-OECD Countries } & \multicolumn{2}{|c|}{ OECD Countries } \\
\hline Log GDP & $\begin{array}{c}2.684 \\
(13.709)\end{array}$ & $\begin{array}{c}-0.494 \\
(-0.374)\end{array}$ & $\begin{array}{c}2.139 \\
(9.218)\end{array}$ & $\begin{array}{c}4.435 \\
(2.846)\end{array}$ & $\begin{array}{c}7.356 \\
(14.588)\end{array}$ & $\begin{array}{l}-69.132 \\
(-7.697)\end{array}$ \\
\hline $\begin{array}{c}\text { (Log GDP) } \\
\text { square }\end{array}$ & $\begin{array}{c}-0.138 \\
(-11.733)\end{array}$ & $\begin{array}{c}0.259 \\
(1.583)\end{array}$ & $\begin{array}{l}-0.104 \\
(-7.375)\end{array}$ & $\begin{array}{c}-0.394 \\
(-2.021)\end{array}$ & $\begin{array}{c}-0.374 \\
(-12.922)\end{array}$ & $\begin{array}{l}8.186 \\
(8.152)\end{array}$ \\
\hline $\begin{array}{c}\text { (Log GDP) } \\
\text { cube }\end{array}$ & - & $\begin{array}{c}-0.016 \\
(-2.435)\end{array}$ & - & $\begin{array}{c}0.012 \\
(1.490)\end{array}$ & - & $\begin{array}{c}-0.318 \\
(-8.528)\end{array}$ \\
\hline $\begin{array}{c}\text { Number of } \\
\text { Observations }\end{array}$ & \multicolumn{2}{|c|}{2700} & \multicolumn{2}{|c|}{2000} & \multicolumn{2}{|c|}{700} \\
\hline $\begin{array}{l}\text { SSR } \\
\text { Log }\end{array}$ & 151.946 & 151.595 & 136.935 & 136.774 & 8.117 & 7.295 \\
\hline $\begin{array}{l}\text { Likelihood } \\
\text { Adjusted }\end{array}$ & 53.468 & 56.586 & -156.479 & -155.307 & 566.725 & 604.117 \\
\hline $\mathrm{R}$ square & 0.978 & 0.977 & 0.969 & 0.969 & 0.960 & 0.964 \\
\hline $\begin{array}{c}\text { Country } \\
\text { Effects } \\
\text { Time }\end{array}$ & 117.000 & 118.176 & 89.765 & 85.681 & 109.327 & 114.998 \\
\hline Effects & 8.820 & 8.265 & 8.382 & 7.287 & 6.812 & 6.449 \\
\hline $\begin{array}{c}\text { Turning } \\
\text { Point }\end{array}$ & 17,084 & 17,116 & 25,000 & 16,068 & 18,891 & 17,873 \\
\hline
\end{tabular}

Footnotes: see notes to Table 1. The turning point is computed numerically. 


\section{Table 3: Carbon Dioxide Emissions - GDP Relationship}

Non-nested Tests of Linear and Log-linear Specifications

\begin{tabular}{|c|c|c|c|c|c|c|}
\hline & \multicolumn{2}{|c|}{ All Countries } & \multicolumn{2}{|c|}{ Non-OECD Countries } & \multicolumn{2}{|c|}{ OECD Countries } \\
\hline & Cubic & Quadratic & Cubic & Quadratic & Cubic & Quadratic \\
\hline & \multicolumn{6}{|c|}{$\mathrm{H}_{0}$ : Linear Model } \\
\hline PE test & 12.550 & 12.684 & 20.840 & 21.222 & 2.973 & 3.089 \\
\hline BM test & -1.465 & -2.029 & 6.023 & 6.395 & -6.235 & -7.248 \\
\hline \multirow[t]{2}{*}{ GW test } & 15.572 & 15.384 & 19.942 & 20.938 & 3.428 & 5.849 \\
\hline & \multicolumn{6}{|c|}{$\mathrm{H}_{0}:$ Log-linear Model } \\
\hline PE test & -5.022 & -3.588 & -6.787 & -8.124 & 4.350 & 5.614 \\
\hline BM test & -8.068 & -8.220 & -9.780 & -10.232 & -3.029 & -3.556 \\
\hline GW test & 6.343 & 2.736 & -3.268 & -2.249 & -0.109 & 8.975 \\
\hline
\end{tabular}

$\mathrm{H}_{0}$ : Linear and Log-linear Models Observationally Equivalent

$\begin{array}{lllllll}\text { BC test } & 3590.4 & 3589.1 & 3672.0 & 3665.7 & 40.212 & 9.730\end{array}$

Footnotes:

(1) PE is a test proposed by MacKinnon, White, and Davidson (1983) for testing linear versus log-linear models (and vice versa); similarly, BM is a test due to Bera and McAleer (1989); GW is a test suggested by Godfrey and Wickens (1981).

(2) In the case of the PE and BM test, the figures reported are the t-statistics of the coefficient of the relevant variable in the comprehensive model on which the non-nested tests are based. In the case of the GW test, the figure reported is the t-statistics of the additional regressor in the modified linear or log-linear model.

(3) BC is Box and Cox (1964)'s test of observational equivalence between linear and loglinear specifications. The test is distributed $\chi^{2}$ with one degree of freedom. 


\section{Table 4: Carbon Dioxide Emissions - GDP Relationship Alternative Functional Forms}

\begin{tabular}{|c|c|c|c|c|c|c|}
\hline & \multicolumn{2}{|c|}{ All Countries } & \multicolumn{2}{|c|}{ Non-OECD Countries } & \multicolumn{2}{|c|}{ OECD Countries } \\
\hline & Gamma & Weibull & Gamma & Weibull & Gamma & Weibull \\
\hline$\alpha$ & $\begin{array}{c}1.682 \\
(45.907)\end{array}$ & $\begin{array}{c}1.588 \\
(59.703)\end{array}$ & $\begin{array}{c}1.584 \\
(38.493)\end{array}$ & $\begin{array}{c}1.529 \\
(47.988)\end{array}$ & $\begin{array}{c}4.902 \\
(4.450)\end{array}$ & $\begin{array}{c}2.159 \\
(18.433)\end{array}$ \\
\hline$\beta$ & $\begin{array}{l}19316.6 \\
(11.573)\end{array}$ & $\begin{array}{l}25334.7 \\
(20.332)\end{array}$ & $\begin{array}{c}30424.2 \\
(5.819)\end{array}$ & $\begin{array}{c}33977.6 \\
(8.376)\end{array}$ & $\begin{array}{c}5230.52 \\
(5.203)\end{array}$ & $\begin{array}{l}21417.2 \\
(35.865)\end{array}$ \\
\hline$\gamma$ & $\begin{array}{l}85.753 \\
(5.210)\end{array}$ & $\begin{array}{l}96.248 \\
(7.083)\end{array}$ & $\begin{array}{l}100.010 \\
(7.116)\end{array}$ & $\begin{array}{c}107.760 \\
(8.376)\end{array}$ & $\begin{array}{l}-4827.76 \\
-(2.495)\end{array}$ & $\begin{array}{r}-346.337 \\
(-0.649)\end{array}$ \\
\hline $\begin{array}{l}\text { Number of } \\
\text { observations }\end{array}$ & & & & & & \\
\hline $\begin{array}{l}\text { SSR } \\
\text { Log }\end{array}$ & 150.097 & 149.745 & 136.686 & 136.718 & 7.347 & 7.507 \\
\hline $\begin{array}{c}\text { Likelihood } \\
\text { Adjusted }\end{array}$ & 69.996 & 73.161 & -154.661 & -154.892 & 601.597 & 594.071 \\
\hline $\mathrm{R}$ square & 0.977 & 0.977 & 0.969 & 0.969 & 0.964 & 0.962 \\
\hline $\begin{array}{c}\text { Turning } \\
\text { Point }\end{array}$ & 13,260 & 13,648 & 17,868 & 17,079 & 15,582 & 15,709 \\
\hline
\end{tabular}

Footnotes: see notes to Table 1. 
Table 5: Carbon Dioxide Emissions - GDP Relationship

Paired Non-nested Tests of Alternative Functional Forms

\begin{tabular}{|c|c|c|c|c|c|c|}
\hline & \multicolumn{2}{|c|}{ All Countries } & \multicolumn{2}{|c|}{ Non-OECD Countries } & \multicolumn{2}{|c|}{ OECD Countries } \\
\hline & Cubic & Quadratic & Cubic & Quadratic & Cubic & Quadratic \\
\hline & \multicolumn{6}{|c|}{ Paired Comparison Non-nested P Test } \\
\hline $\begin{array}{c}\text { Log-linear } \\
\text { vs. } \\
\text { Gamma }\end{array}$ & 5.942 & 5.712 & 1.952 & 2.114 & 8.240 & -0.536 \\
\hline $\begin{array}{c}\text { Log-linear } \\
\text { vs. } \\
\text { Weibull }\end{array}$ & 6.140 & 5.818 & 2.207 & 2.577 & 7.428 & -1.976 \\
\hline $\begin{array}{l}\text { Gamma } \\
\text { vs. } \\
\text { Log-linear }\end{array}$ & -1.984 & -2.965 & 0.583 & 1.329 & -2.423 & 2.229 \\
\hline $\begin{array}{c}\text { Gamma } \\
\text { vs. } \\
\text { Weibull }\end{array}$ & \multicolumn{2}{|c|}{2.480} & & & \multicolumn{2}{|c|}{-4.940} \\
\hline $\begin{array}{l}\text { Weibull } \\
\text { vs. } \\
\text { Log-linear }\end{array}$ & -0.002 & -0.632 & 1.390 & 1.970 & -1.160 & 0.163 \\
\hline $\begin{array}{l}\text { Weibull } \\
\text { vs. } \\
\text { Gamma }\end{array}$ & \multicolumn{2}{|c|}{-0.211} & \multicolumn{2}{|c|}{0.759} & \multicolumn{2}{|c|}{3.044} \\
\hline
\end{tabular}

Observational Equivalence BC Test

Log-linear
and
13.406
0.644
2.486

Gamma

Log-linear

and

16.576

0.409

10.026

Weibull

Weibull

and

3.170

0.234

7.540

Gamma

Footnotes:

(1) The P test is proposed by Davidson and MacKinnon (1981) for testing non-nested nonlinear regression models. The figures are the t-statistics of the coefficient of the relevant variable in the comprehensive model on which the non-nested tests are based.

(2) BC is Box and Cox (1964)'s test of observational equivalence between alternative functional forms. The test is distributed $\chi^{2}$ with one degree of freedom. The figures refer to the estimated cubic log-linear model. 
Table 6: Carbon Dioxide Emissions - GDP Relationship Multiple Non-nested Tests of Alternative Functional Forms

\begin{tabular}{|c|c|c|c|}
\hline & All Countries & Non-OECD Countries & OECD Countries \\
\hline \multirow{3}{*}{ P test } & & $\mathrm{H}_{0}$ : Log-linear Functional Form & \\
\hline & 16.930 & 7.260 & 29.364 \\
\hline & & $\mathrm{H}_{0}$ : Gamma Functional Form & \\
\hline \multirow[t]{2}{*}{$P$ test } & 5.433 & 6.393 & 31.882 \\
\hline & & $\mathrm{H}_{0}$ : Weibull Functional Form & \\
\hline P test & 3.893 & 6.571 & 31.882 \\
\hline \multicolumn{4}{|l|}{ Degrees of } \\
\hline \multicolumn{4}{|l|}{$\begin{array}{c}\text { Critical } \\
\text { Value }\end{array}$} \\
\hline $5 \%$ & 2.999 & 3.000 & 3.009 \\
\hline $1 \%$ & 4.613 & 4.616 & 4.638 \\
\hline
\end{tabular}

Footnotes: The test is a generalization of the P test proposed by Davidson and MacKinnon (1981) for testing multiple non-nested non-linear regression models. The figures are the F statistics of the zero restriction on the coefficients of the relevant variables in the comprehensive model on which the non-nested tests are based. 


\section{Table 7: Carbon Dioxide Emissions - GDP Relationship Model Selection of Alternative Functional Forms}

\begin{tabular}{cccc}
\hline & All Countries & Non-OECD Countries & OECD Countries \\
\hline Linear & 2164.29 & Residual Sum of Squares & \\
Log-linear & 151.595 & 5345.50 & 7.095 \\
Gamma & 150.097 & 136.774 & 7.295 \\
Weibull & 149.745 & 136.686 & 7.347 \\
& & 136.718 & 7.507 \\
Log-linear & 56.586 & Maximized Log-likelihood & \\
Gamma & 69.996 & -155.307 & 604.117 \\
Weibull & 73.161 & -154.661 & 601.597 \\
\hline
\end{tabular}

Footnotes: The residual sum of squares of the linear model is "corrected" to make it comparable with that of the log-linear model (Box and Cox, 1964; Sargan, 1964). The log-linear model considered in the table is the cubic specification. Aside from time and country effects, all the estimated models of the table are characterized by three parameters. 
Figure 1: Estimated Linear Functional Form

(Turning points in Brackets)

All Countries

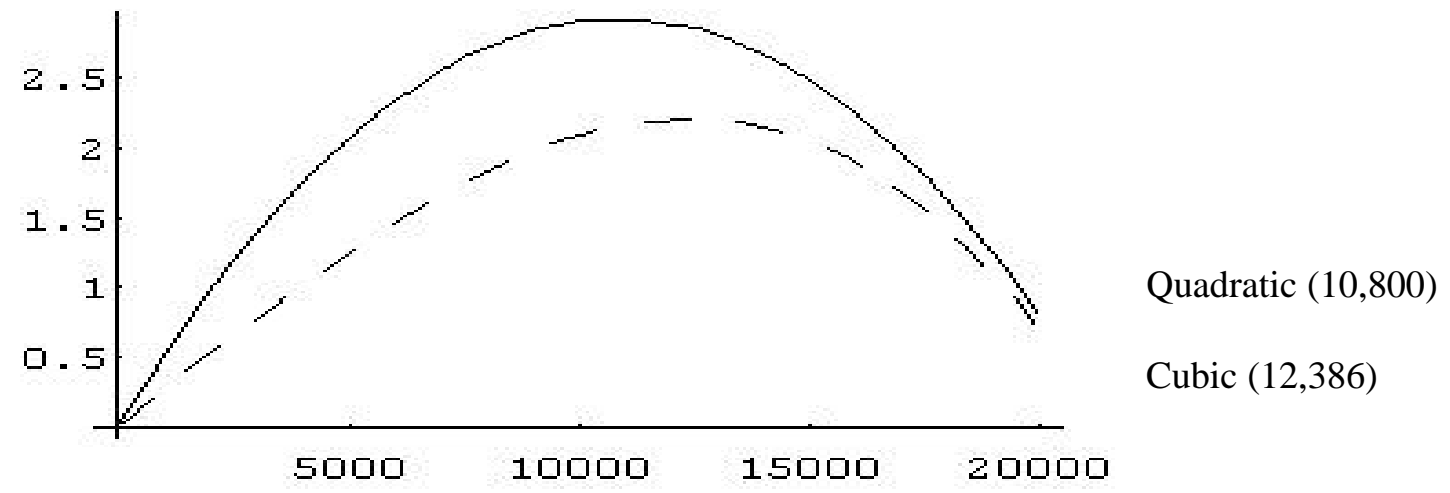

Non OECD Countries

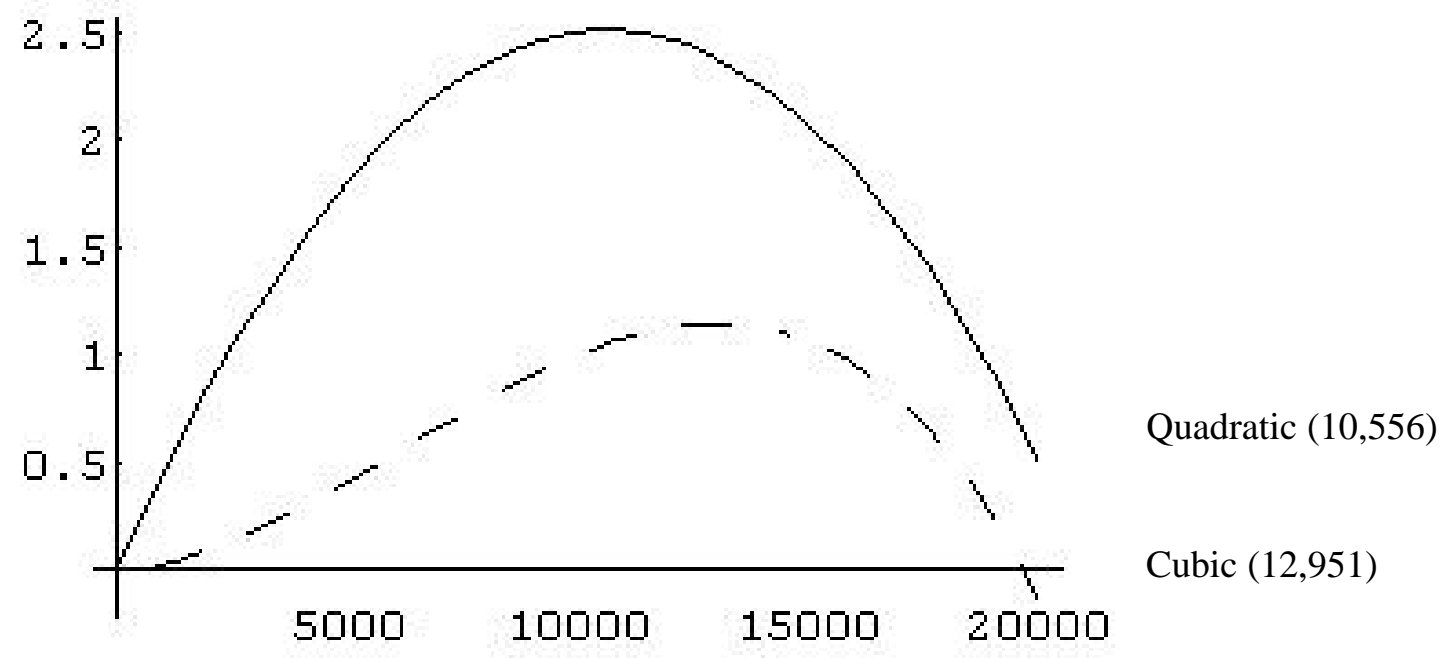

OECD Countries

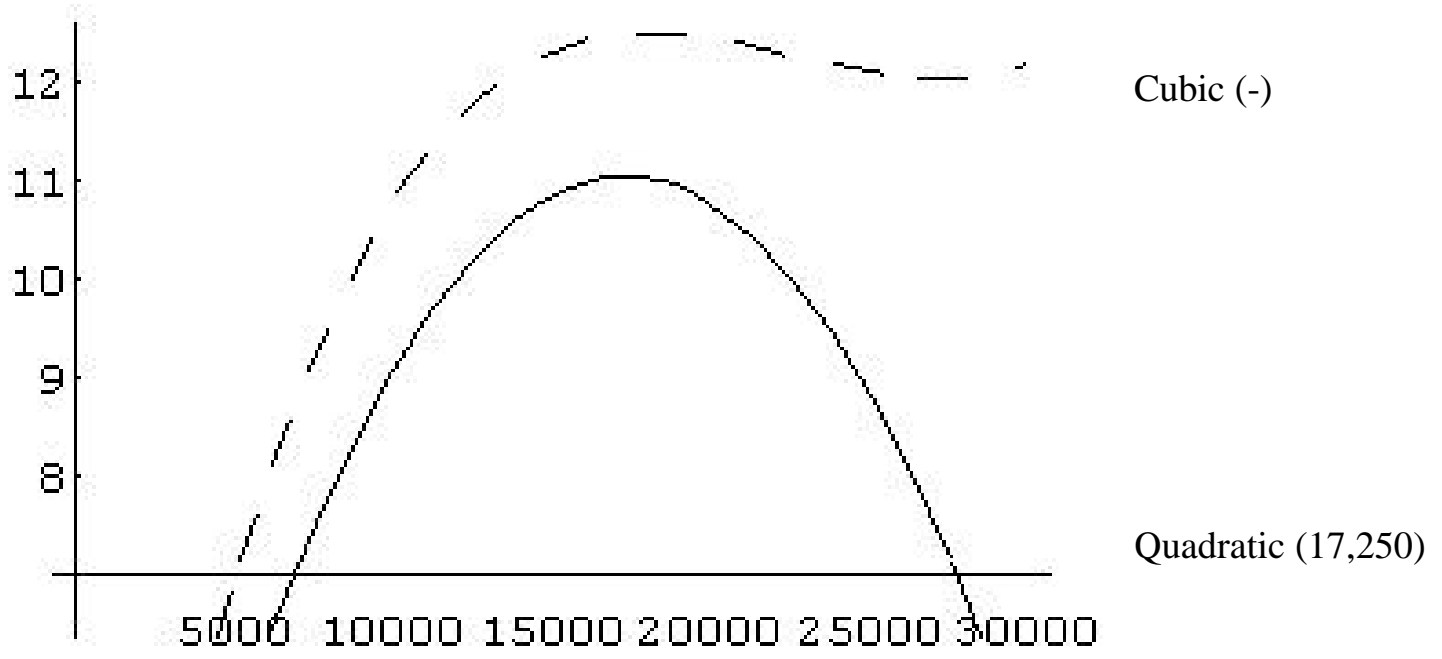




\section{Figure 2: Estimated Log-Linear Functional Form}

(Turning points in Brackets)

All Countries

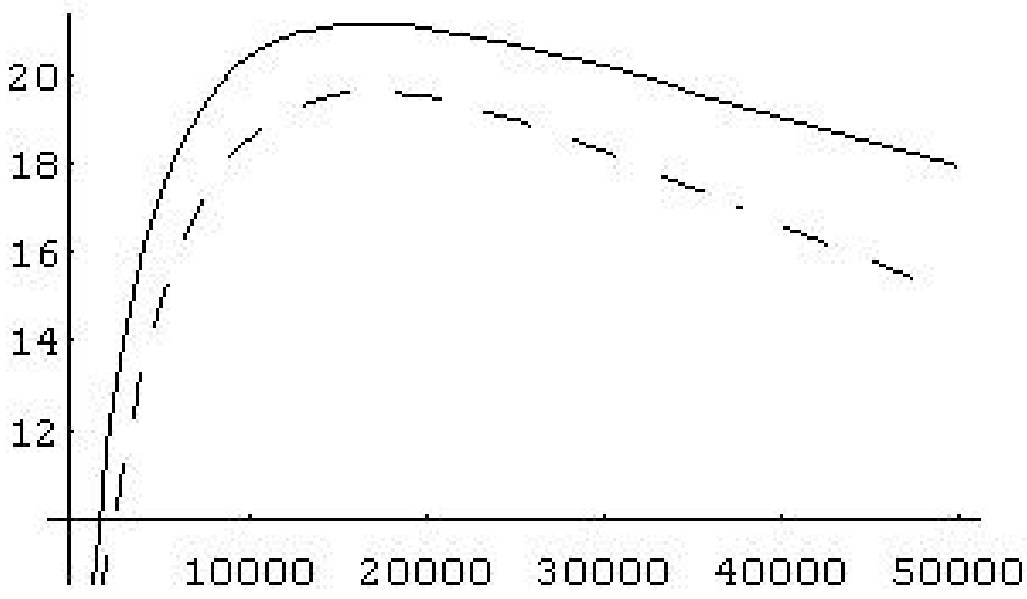

Quadratic (17,084)

Cubic $(17,116)$

Non OECD Countries

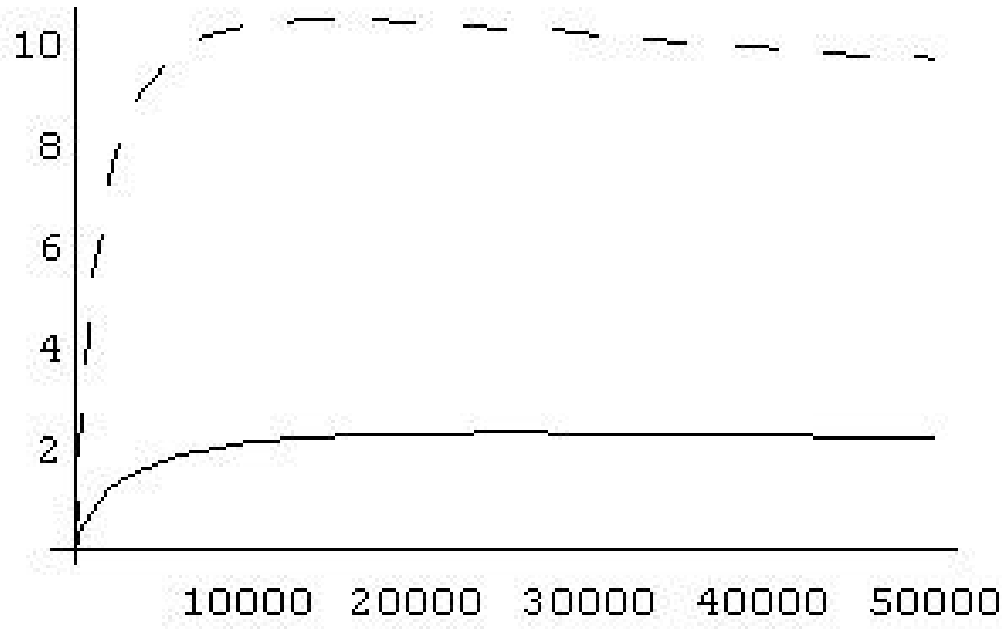

Cubic $(16,068)$

Quadratic $(25,000)$

OECD Countries

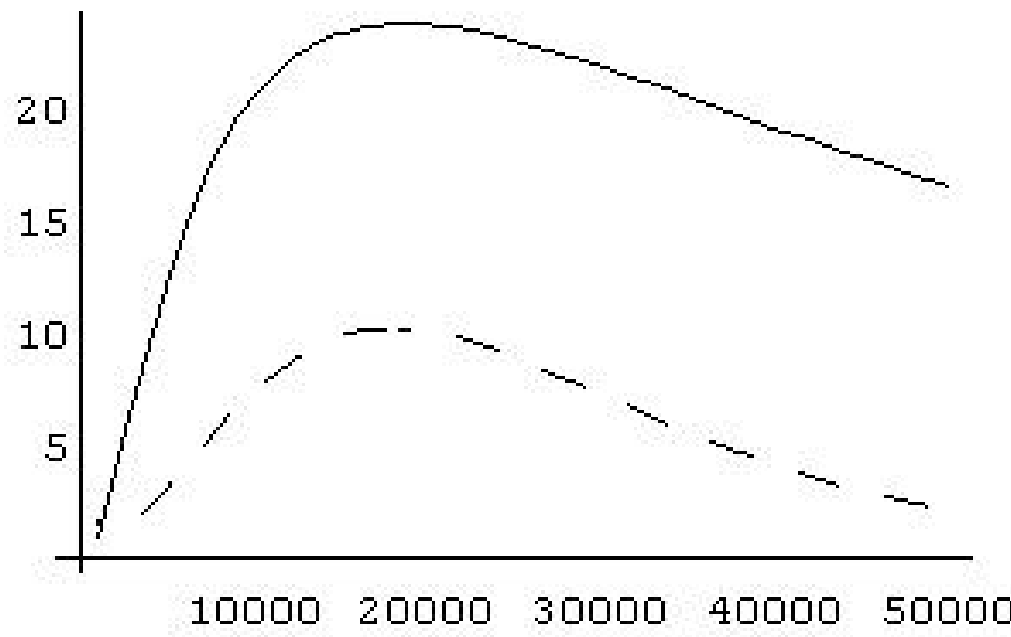

Quadratic $(18,891)$

Cubic $(17,873)$ 
Figure 3: Theoretical Gamma Functions

$$
\log C O_{2}=\theta+(\alpha-1) \log [(G D P-\gamma) / \beta]-[(G D P-\gamma) / \beta]
$$

Changes in $\alpha$ parameter

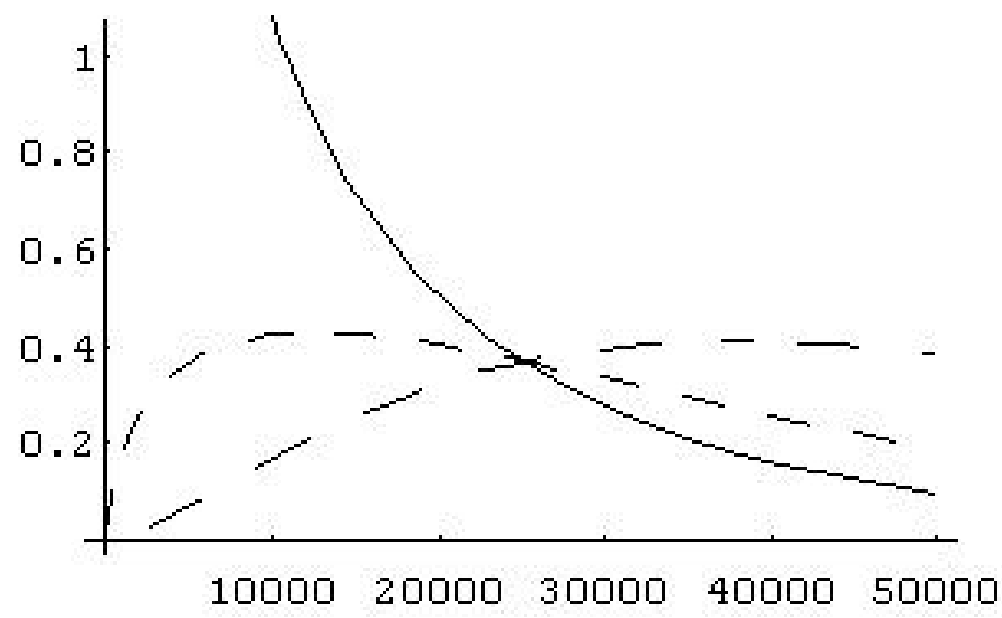

$$
\begin{aligned}
& \theta=0 \\
& \alpha=0.5,2,2.5 \\
& \beta=25000 \\
& \gamma=100
\end{aligned}
$$

Changes in $\beta$ parameter

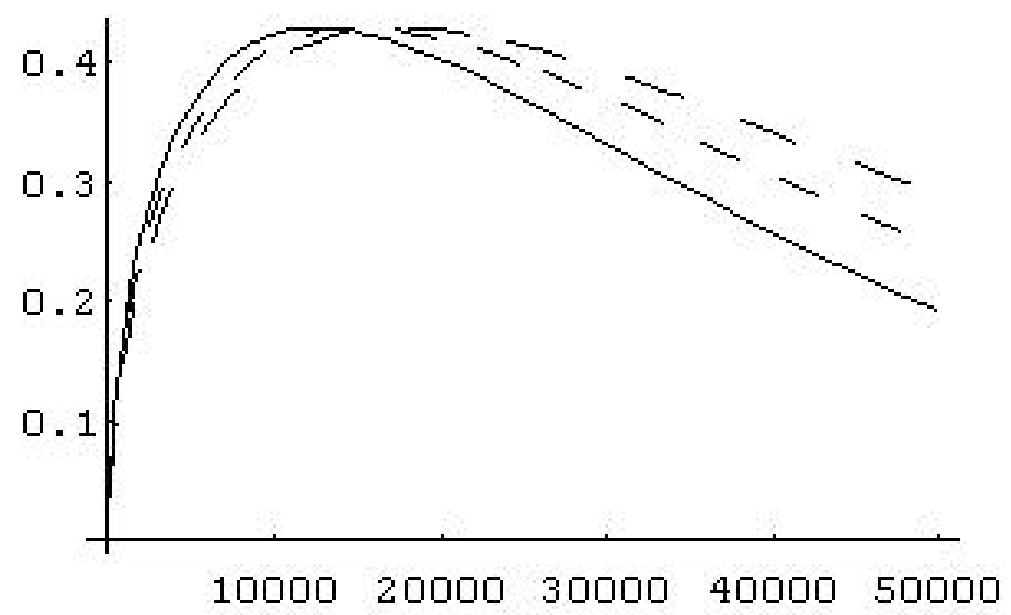

$$
\begin{aligned}
& \theta=0 \\
& \alpha=1.5 \\
& \beta=25000,30000,35000 \\
& \gamma=100
\end{aligned}
$$

Changes in $\gamma$ parameter

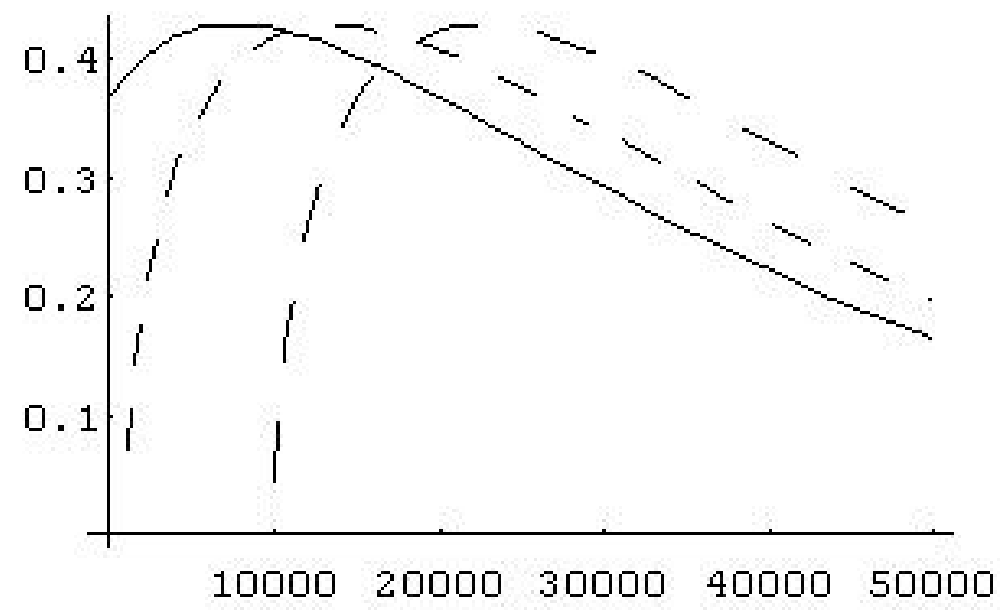

$$
\begin{aligned}
& \theta=0 \\
& \alpha=1.5 \\
& \beta=25000 \\
& \gamma=-5000,1000,10000
\end{aligned}
$$


Figure 4: Theoretical Weibull Functions

$\log C O_{2}=\theta+(\alpha-1) \log [(G D P-\gamma) / \beta]-[(G D P-\gamma) / \beta]^{\alpha}$

Changes in $\alpha$ parameter

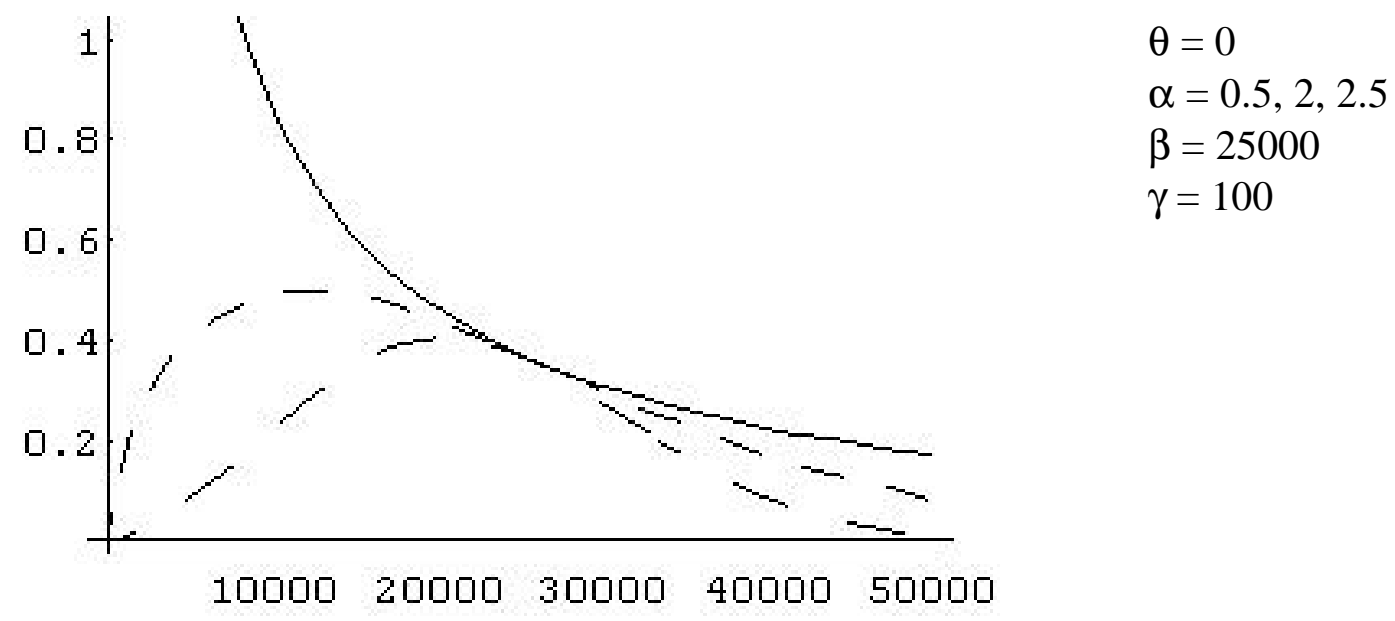

Changes in $\beta$ parameter

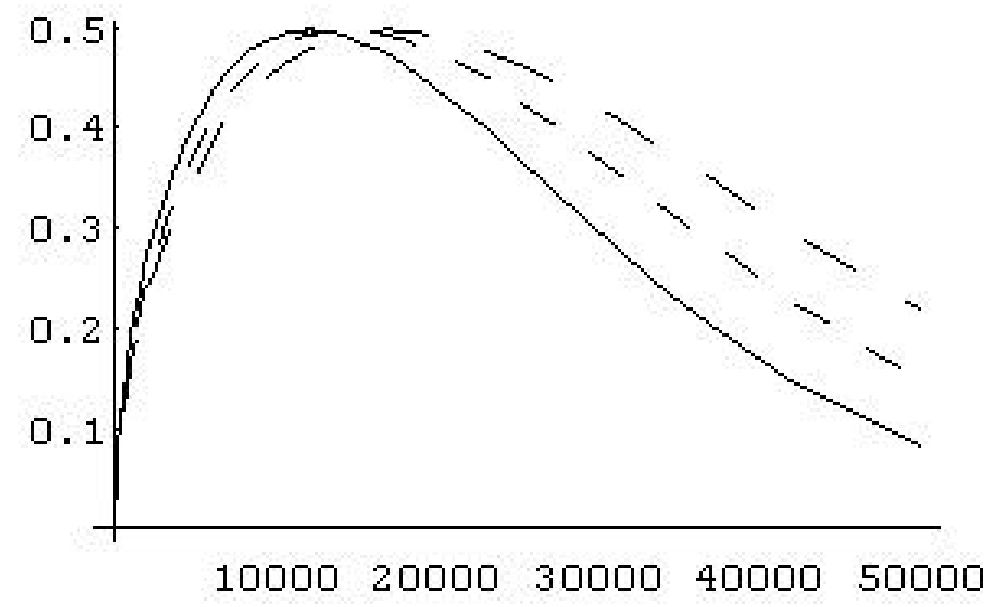

$$
\begin{aligned}
& \theta=0 \\
& \alpha=1.5 \\
& \beta=25000,30000,35000 \\
& \gamma=100
\end{aligned}
$$

Changes in $\gamma$ parameter

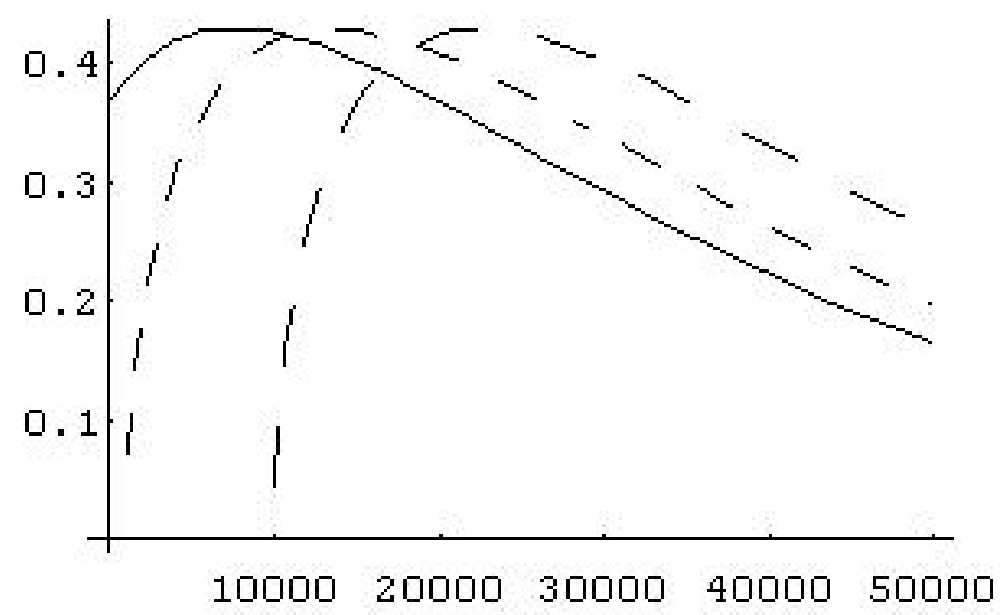

$$
\begin{aligned}
& \theta=0 \\
& \alpha=1.5 \\
& \beta=25000 \\
& \gamma=-5000,1000,10000
\end{aligned}
$$


Figure 5: Estimated Gamma and Weibull Functional Forms

(Turning points in Brackets)

All Countries

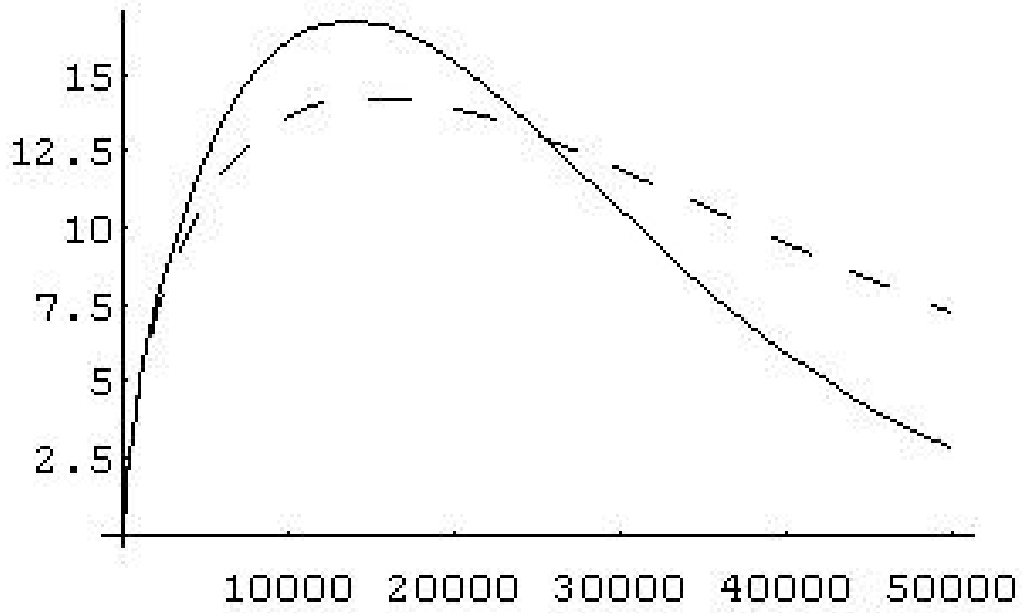

Non OECD Countries

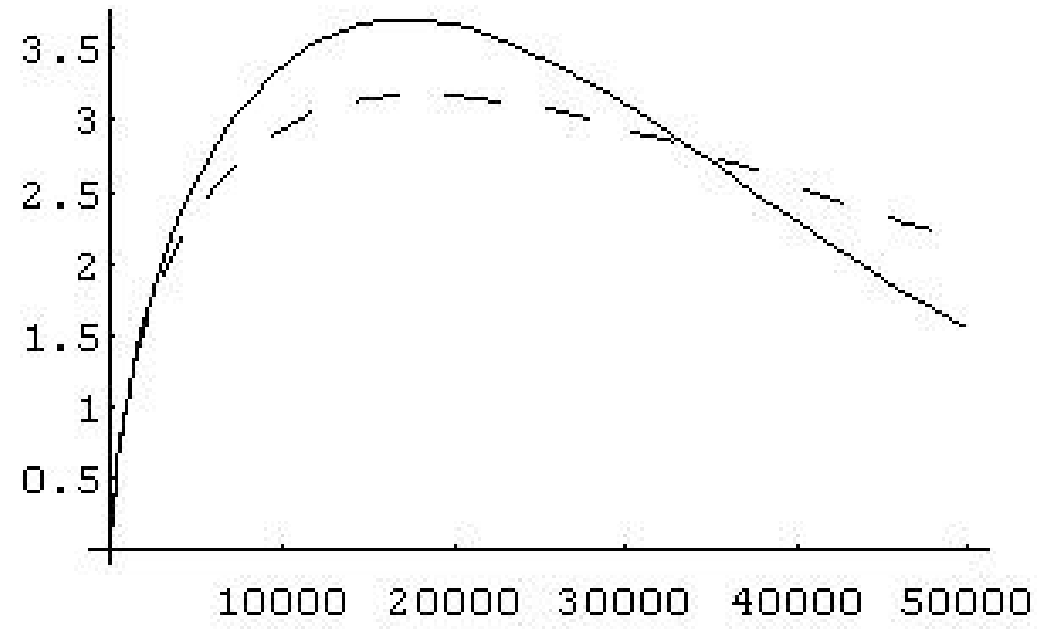

OECD Countries

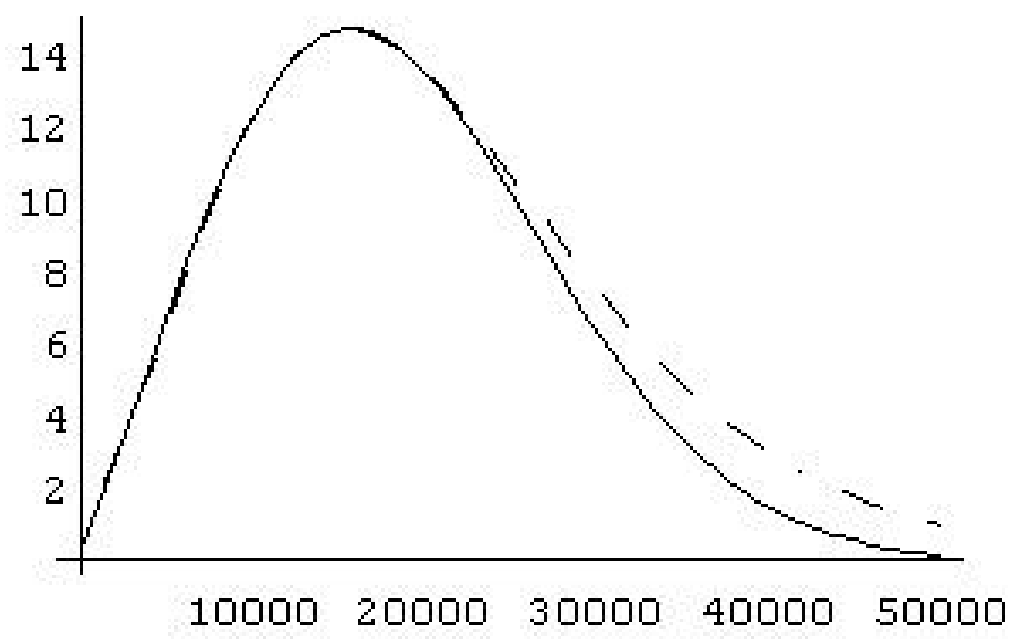

Gamma $(17,240)$

Weibull $(17,260)$

Gamma $(15,585)$

Weibull $(15,700)$ 


\section{DESPERATELY SEEKING (ENVIRONMENTAL) KUZNETS}

\section{Appendix A: Curvature and Turning Points in the Linear and Log-linear Models}

Consider the linear-in-variables model:

$$
y=\alpha_{0}+\alpha_{1} x+\alpha_{2} x^{2}+\alpha_{3} x^{3}
$$

We are especially interested in the behavior of the first two derivatives and in the expression for $x$, call it "turning point" $x^{T P}$, which results from setting the first derivative equal to zero. In what follows we will assume $\alpha_{0}>0$ and $\alpha_{1}>0$. The first and second derivatives are:

$$
\begin{aligned}
& d y / d x=\alpha_{1}+2 \alpha_{2} x+3 \alpha_{3} x^{2} \\
& d^{2} y / d x^{2}=2 \alpha_{2}+6 \alpha_{3} x
\end{aligned}
$$

Consider first the case of a quadratic specification by imposing $\alpha_{3}=0$ in (A1). In this case $d^{2} y / d x^{2}=2 \alpha_{2}$ and the function exhibits an inverted-U shape if $\alpha_{2}<0$. Also, given $d y / d x=\alpha_{1}+2 \alpha_{2} x=0$, we obtain $x^{T P}=-\alpha_{1} / 2 \alpha_{2}$ which is positive as long as $\alpha_{2}<0$. Hence, the emergence of the EKC hinges upon the sign of $\alpha_{2}$.

When $\alpha_{3} \neq 0$, according to some authors (Ekins, 1997; de Bruyn et al., 1998) the function in (A1) may exhibit a $\mathrm{N}$-shape with an upper turning point followed by a lower turning point if $\alpha_{2}<0$ and $\alpha_{3}>0$. In fact the case of a cubic specification is more complex and requires the analysis of several possibilities.

(i) Suppose $\alpha_{2}=0$ and $\alpha_{3} \neq 0$. We have: $d y / d x=\alpha_{1}+3 \alpha_{3} x^{2}$ and $d^{2} y / d x^{2}=6 \alpha_{3} x$. Note that:

$$
x^{T P}= \pm \sqrt{\frac{\alpha_{1}}{-3 \alpha_{3}}}
$$

Clearly, if $\alpha_{3}>0$ then $x^{T P}$ is a complex number. We therefore restrict $\alpha_{3}$ to be negative. Moreover, since there are two possible solutions, we may rule out a negative $x^{T P}$. Hence: $x^{T P}=\left(-\alpha_{1} / 3 \alpha_{3}\right)^{1 / 2}>0$. With $\alpha_{3}<0$ it also follows that $d^{2} y / d x^{2}<0$ and we conclude that an EKC can emerge.

(ii) Suppose now $\alpha_{2}>0$ and $\alpha_{3} \neq 0$. The expression for the turning point is: 


$$
x^{T P}=\frac{-2 \alpha_{2} \pm \sqrt{4 \alpha_{2}{ }^{2}-12 \alpha_{1} \alpha_{3}}}{6 \alpha_{3}}
$$

which can be either positive or negative. Let us assume that $x^{T P}$ is positive. To proceed with the curvature of the function we need to further distinguish:

(ii-a) $\alpha_{2}>0$ and $\alpha_{3}<0$. In this case $d^{2} y / d x^{2}$ can be either positive or negative and the function may turn out to be either convex or concave. As for the turning point, we note that there are two real distinct roots; in addition, there is the possibility of two positive turning points. Because $d^{2} y / d x^{2} \neq 0$, if one turning point is a minimum of the function the other will be a maximum but we cannot tell a priori which is which.

(ii-b) $\alpha_{2}>0$ and $\alpha_{3}>0$. Here there cannot be multiple positive turning points, although similar conclusions as before hold for the curvature of the function.

(iii) Finally, suppose $\alpha_{2}<0$ and $\alpha_{3} \neq 0$. The turning point may or may not be a complex number. In particular:

(iii-a) $\alpha_{2}<0$ and $\alpha_{3}<0$. In this case $x^{T P}$ is a real number and we assume that it is a positive one. The second derivative of the function is negative and therefore an EKC may emerge.

(iii-b) $\alpha_{2}<0$ and $\alpha_{3}>0$. There is no guarantee of $x^{T P}$ not being imaginary. Assuming it is real, it may be positive or negative. Even ruling out the latter possibility, the function is of a priori uncertain curvature as $d^{2} y / d x^{2}$ may be positive or negative.

Consider now the log-linear specification. In this case the curvature and turning point of the function cannot be easily predicted analytically. The reason is that, while logarithmic derivatives can be easily computed, we are in general interested in the level, or non-logarithmic, derivatives. The relationship between them is the following:

$$
\begin{aligned}
& \frac{d y}{d x}=\frac{d \ln y}{d \ln x} \frac{y}{x} \\
& \frac{d^{2} y}{d x^{2}}=\frac{y}{x^{2}}\left[\frac{d^{2} \ln y}{d(\ln x)^{2}}+\frac{d \ln y}{d \ln x}\left(\frac{d \ln y}{d \ln x}-1\right)\right]
\end{aligned}
$$

To find the turning point $x^{T P}$ we must solve $d y / d x=0$. Now let the general (cubic) log-linear model be:

$$
\ln y=\alpha_{0}+\alpha_{1} \ln x+\alpha_{2}(\ln x)^{2}+\alpha_{3}(\ln x)^{3}
$$


or:

$$
y=e^{\alpha_{0}} x^{\alpha_{1}} e^{\alpha_{2}(\ln x)^{2}} e^{\alpha_{3}(\ln x)^{3}}
$$

It can be shown that:

$$
\begin{aligned}
\frac{d y}{d x}= & {\left[\alpha_{1}+2 \alpha_{2} \ln x+3 \alpha_{3}(\ln x)^{2}\right](y / x) } \\
= & {\left[\alpha_{1}+2 \alpha_{2} \ln x+3 \alpha_{3}(\ln x)^{2}\right] e^{\alpha_{0}} x^{\alpha_{1}-1} e^{\alpha_{2}(\ln x)^{2}} e^{\alpha_{3}(\ln x)^{3}} } \\
\frac{d^{2} y}{d x^{2}}= & \left\{\left(2 \alpha_{2}+6 \alpha_{3} \ln x\right)+\left[\alpha_{1}+2 \alpha_{2} \ln x+3 \alpha_{3}(\ln x)^{2}\right]\right. \\
& {\left.\left[\alpha_{1}-1+2 \alpha_{2} \ln x+3 \alpha_{3}(\ln x)^{2}\right]\right\}\left(y / x^{2}\right) } \\
= & \left(2 \alpha_{2}+6 \alpha_{3} \ln x\right)+\left[\alpha_{1}+2 \alpha_{2} \ln x+3 \alpha_{3}(\ln x)^{2}\right] \\
& {\left[\alpha_{1}-1+2 \alpha_{2} \ln x+3 \alpha_{3}(\ln x)^{2}\right] e^{\alpha_{0}} x^{\alpha_{1}-2} e^{\alpha_{2}(\ln x)^{2}} e^{\alpha_{3}(\ln x)^{3}} }
\end{aligned}
$$

From (A10)-(A11) it emerges that the log-linear specification does not yield a closed form expression for the turning point, unlike the linear-in-variables functional form. Moreover, curvature and turning point cannot be easily predicted a priori on the basis of the sign of the function parameters.

\section{References}

de Bruyn, S.M., J.C.J.M. van den Bergh, and J.B. Opschoor (1998), "Economic Growth and

Emissions: Reconsidering the Empirical Basis of Environmental Kuznets Curves", Ecological Economics, 25, 161-175.

Ekins, P. (1997), The Kuznets Curve for the Environment and Economic Growth: Examining the Evidence", Environment and Planning A, 29, 805-830.

\section{Appendix B: Non-nested Tests of Alternative Functional Forms}

It is well known that a feature of tests of separate regression structures is that the null of each specification has to be tested against the alternative. Thus, in the case of two models, a nonnested test has to be conducted twice. Unlike standard tests, this implies that both specifications may be rejected in favor of the alternative. 
Generally speaking, the tests we consider are tests in regression direction, in that each individual model is contrasted against a comprehensive model artificially nesting both structures, rather than directly against a specific competing alternative. Such tests are tests of model specification, rather than of model selection. However, we also consider a criterion and an associated test which permit the selection of a specific model out of several alternatives.

In keeping with the EKC literature, we first consider non-nested tests of linear and log-linear regression models. We then consider tests of the alternative functional forms proposed in the paper, namely, three parameter Gamma and Weibull.

\section{(i) Non-nested Tests of Linear and Log-linear Regression Models}

This issue is the subject of a remarkable number of contributions to the theoretical and applied econometrics literature (see, among others, Davidson and MacKinnon, 1985; Godfrey, McAleer, and McKenzie, 1988; Bera and McAleer, 1989).

From the viewpoint of the theory of non-nested hypothesis tests, the peculiarity of this problem is that the left-hand side variable is not the same in the two models, but one is a known monotonic transformation of the other. This calls for especially designed non-nested tests. There are several possibilities and, following Godfrey, McAleer, and McKenzie (1988), we have considered three alternative tests. Let the two model structures be given by:

$$
\begin{aligned}
& \mathrm{H}_{1}: \log y=\beta_{0}+\sum_{i}^{k} \beta_{i} \log x_{i}+\varepsilon_{1} \\
& \mathrm{H}_{2}: y=\gamma_{0}+\sum_{i}^{k} \gamma_{i} x_{i}+\varepsilon_{2}
\end{aligned}
$$

The first test is the so-called PE (i.e. extended projection) test proposed by MacKinnon, White, and Davidson (1983). The PE test is based upon the following artificial regression models:

$$
\begin{aligned}
& \log y-\log \tilde{y}=\beta_{0}+\sum_{i}^{k} \beta_{i} \log x_{i}+\alpha_{1}[\tilde{y}-\exp (\log \hat{y})]+\varepsilon \\
& y-\tilde{y}=\gamma_{0}+\sum_{i}^{k} \gamma_{i} x_{i}+\alpha_{2}[\log \hat{y}-\log \tilde{y}]+\varepsilon
\end{aligned}
$$

where $\log \hat{y}$ and $\tilde{y}$ are the fitted values of (B1) and (B2) respectively. It can be shown that the PE tests of $\mathrm{H}_{1}$ and $\mathrm{H}_{2}$ are equivalent to testing $\alpha_{1}=0$ and $\alpha_{2}=0$ in the following regressions (which are asymptotically equivalent to (B3)-(B4)): 


$$
\begin{aligned}
& \log y=\beta_{0}+\sum_{i}^{k} \beta_{i} \log x_{i}+\alpha_{1} \log \tilde{y}+\varepsilon \\
& y=\gamma_{0}+\sum_{i}^{k} \gamma_{i} x_{i}+\alpha_{2} \exp (\log \hat{y})+\varepsilon
\end{aligned}
$$

Under the corresponding null hypothesis each statistics is asymptotically distributed as $N(0,1)$ variates.

Bera and McAleer (1989) propose a test which is based upon the following two regression models:

$$
\begin{aligned}
& \log \tilde{y}=\beta_{0}+\sum_{i}^{k} \beta_{i} \log x_{i}+\eta_{1} \\
& \exp (\log \hat{y})=\gamma_{0}+\sum_{i}^{k} \gamma_{i} x_{i}+\eta_{2}
\end{aligned}
$$

These models again use the fitted values of (B1)-(B2). Their estimation yields the residuals denoted $\tilde{\eta}_{1}$ and $\hat{\eta}_{2}$. These residuals are in turn used in the following regressions:

$$
\begin{aligned}
& \log y=\beta_{0}+\sum_{i}^{k} \beta_{i} \log x_{i}+\theta_{1} \hat{\eta_{2}}+\varepsilon \\
& y=\gamma_{0}+\sum_{i}^{k} \gamma_{i} x_{i}+\theta_{2} \tilde{\eta}_{1}+\varepsilon
\end{aligned}
$$

The tests, denoted as $\mathrm{BM}$, of $\mathrm{H}_{1}$ and $\mathrm{H}_{2}$ are based on the estimation of $\theta_{1}$ and $\theta_{2}$. If the disturbances of (B1) and (B2) are normally distributed, the test under the corresponding null hypothesis is exactly distributed as Student $t$ in finite samples. However, the normality assumption for $\varepsilon_{1}$ is inconsistent with the logarithmic transformation of $y$. However, it can be shown that asymptotically the $\mathrm{BM}$ test is distributed as $N(0,1)$ variates underthe respective null hypothesis.

Finally, linear and log-linear specifications can be regarded as special cases of the Box-Cox (1964) regression model:

$$
\mathrm{H}_{\mathrm{BC}}: y(\lambda)=\beta_{0}+\sum_{i}^{k} x_{i}(\lambda)+\varepsilon
$$

where $z(\lambda)=\left(z^{\lambda}-1\right) / \lambda$ denotes the Box-Cox transformation. The model in (B11) reduces to the log-linear specification $\mathrm{H}_{1}$ when $\lambda=0$ and to the linear specification $\mathrm{H}_{2}$ when $\lambda=1$. Several tests based on the Box-Cox model have been devised (Davidson and MacKinnon, 1985; Godfrey, 
McAleer, and McKenzie, 1988). One such test is proposed by Godfrey and Wickens (1981), whose suggested strategy leads to $\mathrm{H}_{1}$ and $\mathrm{H}_{2}$ being tested, respectively, against:

$$
\begin{aligned}
& \log y=\beta_{0}+\sum_{i}^{k} \beta_{i} \log x_{i}+\lambda\left[.5 \sum_{i}^{k} \hat{\beta}_{i}\left(\log x_{i}\right)^{2}-.5(\log \hat{y})^{2}\right]+\varepsilon_{1} \\
& y=\gamma_{0}+\sum_{i}^{k} \gamma_{i} x_{i}+(1-\lambda)\left[(\tilde{y} \log \tilde{y}-\tilde{y}+1)-\sum_{i}^{k} \tilde{\gamma}_{i}\left(x_{i} \log x_{i}-x_{i}+1\right)\right]+\varepsilon_{2}
\end{aligned}
$$

where $\hat{\beta}_{i}$ and $\tilde{\gamma}_{i}$ are the estimated coefficients of (B1) and (B2) respectively. The $t$-statistics of $\lambda=0$ in (B12) and of $\lambda=1$ in (B13) are asymptotically normally distributed under the respective null of this test, denoted GW.

\section{(ii) Non-nested Tests of Non-linear Regression Models}

The discrimination between Gamma and Weibull functional forms calls for a test for non-nested non-linear models. One such test is the P test (P for "Prediction") developed by Davidson and MacKinnon (1981). The two competing models can be represented as follows:

$$
\begin{aligned}
& \mathrm{H}_{1}: y=f(X, \beta)+\varepsilon_{1} \\
& \mathrm{H}_{2}: y=g(Z, \gamma)+\varepsilon_{2}
\end{aligned}
$$

where $X$ and $Z$ are the explanatory variables and $\beta$ and $\gamma$ are the associated parameter vectors. The idea is to form the artificial comprehensive model:

$$
\mathrm{H}_{\mathrm{C}}: y=(1-a) f(X, \beta)+a g(Z, \gamma)+\varepsilon
$$

When $a=0 \mathrm{H}_{\mathrm{C}}$ collapses to $\mathrm{H}_{1}$; when $a=1, \mathrm{H}_{\mathrm{C}}$ collapses to $\mathrm{H}_{2}$. The problem with implementing (B16) is that in general not all the parameters are identified. Davidson and MacKinnon (1981) therefore suggest replacing the parameters of the model that is not being tested with those that would be consistent if the data generation process actually belonged to the model for which they are defined. When testing, say, $\mathrm{H}_{1}, g(Z, \gamma)$ in (B16) is replaced by the fitted value $\hat{g}=g(Z, \hat{\gamma})$. The non-linear nature of (B13), in addition, suggests to linearize (B16) about $a=0, \beta=\hat{\beta}$ yielding:

$$
\mathrm{H}_{\mathrm{c}}{ }^{\prime}: y-\hat{f}=a(\hat{g}-\hat{f})+\hat{F} b+\varepsilon
$$

where $\hat{f}$ and $\hat{g}$ are the fitted values of (B14) and (B15) respectively, and $\hat{F}$ is the row vector of derivatives of $f($.$) with respect to \beta$ evaluated at $\hat{\beta}$. The test of model $\mathrm{H}_{1}$ against $\mathrm{H}_{\mathrm{c}}$ ' entails examining the statistical significance of $a$ in (B17). To test the null of model $\mathrm{H}_{2}$ against $\mathrm{H}_{\mathrm{c}}{ }^{\prime}$, the 
role of $\hat{f}$ and $\hat{g}$ is reversed with $\hat{F}$ replaced by $\hat{G}$ is the row vector of derivatives of $g($.$) with$ respect to $\gamma$ evaluated at $\hat{\gamma}$.

(iii) Multiple Comparison Non-nested Tests

The non-nested tests considered above assumed that there was only one alternative specification to be contrasted with the one under the null hypothesis. As in the case of the present paper, this is not so however, and a more appropriate procedure requires considering an alternative hypothesis that comprise all alternative specifications simultaneously. The generalization of Davidson and MacKinnon (1981) P test to the case of multiple non-nested non-linear regression models is straightforward (see for instance Smith and Smyth, 1990). Suppose we have the following three competing models:

$$
\begin{aligned}
& \mathrm{H}_{1}: y=f(X, \beta)+\varepsilon_{1} \\
& \mathrm{H}_{2}: y=g(Z, \gamma)+\varepsilon_{2} \\
& \mathrm{H}_{3}: y=h(W, \delta)+\varepsilon_{3}
\end{aligned}
$$

The artificial comprehensive model is:

$$
\mathrm{H}_{\mathrm{C}}: y=\left(1-a_{1}-a_{2}\right) f(X, \beta)+a_{1} g(Z, \gamma)+a_{2} h(W, \delta)+\varepsilon
$$

The operational version of (B22) then becomes:

$$
\mathrm{H}_{\mathrm{c}} \cdot y-\hat{f}=a_{1}(\hat{g}-\hat{f})+a_{2}(\hat{h}-\hat{f})+\hat{F} b+\varepsilon
$$

where $\hat{f}, \hat{g}$, and $\hat{h}$ are the fitted values of (B18)-(B20) respectively, and $\hat{F}$ is again the row vector of derivatives of $f($.$) with respect to \beta$ evaluated at $\hat{\beta}$. The test having $\mathrm{H}_{1}$ as the null hypothesis entails testing $a_{1}=a_{2}=0$ in (B22). To test the null of the other models, we proceed in a similar way, with $\hat{f}$ suitably replaced by $\hat{g}$ or $\hat{h}$ and with $\hat{F}$ replaced by $\hat{G}$ or $\hat{H}$, the row vectors of derivatives respectively of $g($.$) with respect to \gamma$ evaluated at $\hat{\gamma}$ and of $h($.$) with$ respect to $\delta$ evaluated at $\hat{\delta}$.

(iv) $\underline{\text { Model Selection }}$ 
As noted by, among others, Davidson and MacKinnon (1981), the procedures described above are really designed for testing model specification, not for choosing among a number of competing models. If one wants to select one specification among several alternatives, one should use some sort of information criterion.

A typical procedure rests upon the comparison of maximized likelihood values: one model is preferred to another if its maximized log-likelihood value is greater than that of the other model (see Sargan, 1964). When the number of parameters differs substantially across competing models, it is advisable to take into account of this fact. A popular procedure is Akaike (1974)'s information criterion (denoted as AIC), which is nothing but a likelihood comparison together with a penalization of structures with more estimated parameters. In symbols:

$$
A I C_{i}=-2 \log L_{i}+2 k_{i}
$$

where $\log L$ is the $\log$-likelihood value of the $i$-th estimated model having $k$ estimated parameters. The preferred model is the one with smallest AIC. Other information criteria are available in the literature. However, when the number of parameters does not differ significantly across competing models, as in the case of the comparison between log-linear, Gamma or Weibull functional forms, it is sufficient to look at the likelihood value.

Information criteria such as $A I C$ can be applied to the comparison of models having the same left hand side variable. This is not the case when a choice is to be made between linear and log-linear models. A suggestion due to Box and Cox (1964) and applied by Sargan (1964) is to examine the unexplained variation of the two models as measured by the residual sum of squares and choose the specification with the smallest unexplained variation. However, the dependent variable of linear and of log-linear models is measured in different units. A way to circumvent this difficulty involves dividing the dependent variable of the linear model $y_{t}$ by its geometric mean $\bar{y}_{G}=\left(y_{1} y_{2} \ldots y_{T}\right)^{1 / T}$. Thus, the "corrected" sum of squared residuals of the linear model $s s r_{L} / \bar{y}_{G}{ }^{2}$ can be directly compared with the sum of squared residuals of the log-linear model, sse $_{L L}$. In addition, Box and Cox (1964) have shown that, under the null hypothesis that the two models are observationally equivalent, the statistics:

$$
B C=\frac{T}{2} \mid \ln \left(\frac{s s r_{L} / \bar{y}_{G}^{2}}{s s r_{L L}}\right)
$$

is distributed $\chi^{2}$ with one degree of freedom. Obviously, this test can also be applied to all models whose dependent variable is measured in comparable units. 
The philosophy behind the above criteria is that the best fitting model is the closest approximation to the data generating process. While computational simplicity and clearcut decisions are the advantages of those criteria, the level of significance associated with the decision is not known.

\section{References}

Akaike, H. (1974), “A New Look at the Statistical Model Idenification”, IEEE Transactions on Automatic Control, 19, 716-723.

Bera, A.K. and M. McAleer (1989), "Nested and Non-nested Procedures for Testing Linear and Log-linear Regression Models", Sankhya, B, 51, 221-224.

Box, G. and D. Cox (1964), “An Analysis of Transformations”, Journal of the Royal Statistical Society, Series B, 211-264.

Davidson, R. and J.G. MacKinnon (1981), "Several Tests for Model Specification in the Presence of Alternative Hypotheses", Econometrica, 49, 781-793.

Davidson, R. and J.G. MacKinnon (1985), "Testing Linear and Loglinear Regressions Against Box-Cox Alternatives", Canadian Journal of Economics, XVIII, 499-517.

Godfrey, L.G. and M.R. Wickens (1981), "Testing Linear and Log-linear Regressions for Functional Form", Review of Economic Studies, 48, 487-496.

Godfrey, L.G., M. McAleer, and C.R. McKenzie (1988), "Variable Addition and Lagrange Multiplier Tests for Linear and Logarithmic Regression Models", Review of Economics and Statistics, LXX, 492-503.

MacKinnon, J.G., H. White, and Davidson, R. (1983), “Tests for Model Specification in the Presence of Alternative Hypotheses: Some Further Results", Journal of Econometrics, $21,53-70$.

Sargan, J.D. (1964), "Wages and Prices in the United Kingdom: A Study in Ecnometric Methodology", in P.E.Hart, G.Mills, and J.Whitaker (eds.), Econometric Analysis for National Economic Planning, London: Butterworth \& Co., 25-54.

Smith, M.A. and D.J. Smyth (1990), "Choosing Among Multiple Nonlinear Non-nested Regression Models with Different Dependent Variables", Economics Letters, 34, 147150.

\section{Appendix C: List of Countries Included in the Sample}




\begin{tabular}{|c|c|}
\hline Yemen & United Arab Emirates \\
\hline Syria & Saudi Arabia \\
\hline Qatar & Oman \\
\hline Lebanon & Jordan \\
\hline Israel & Iraq \\
\hline Iran & Bahrain \\
\hline Other Asian & China \\
\hline Thailand & Taiwan \\
\hline Sri Lanka & Singapore \\
\hline Philippines & Pakistan \\
\hline Nepal & Myanmar \\
\hline Malaysia & Indonesia \\
\hline India & HongKong \\
\hline South Korea & Japan \\
\hline Brunei & Bangladesh \\
\hline USA & Canada \\
\hline Mexico & Other Latin American \\
\hline Venezuela & Uruguay \\
\hline Trinidad & Peru \\
\hline Paraguay & Panama \\
\hline Nicaragua & Jamaica \\
\hline Honduras & Haiti \\
\hline Guatemala & Ecuador \\
\hline El Salvador & Dominican Republic \\
\hline Cuba & Costa Rica \\
\hline Colombia & Chile \\
\hline Brazil & Bolivia \\
\hline Argentina & Other African \\
\hline Zimbabwe & Zambia \\
\hline Zaire & Tunisia \\
\hline Tanzania & Sudan \\
\hline South Africa & Senegal \\
\hline Nigeria & Mozambique \\
\hline
\end{tabular}


Morocco

Kenya

Ghana

Ethiopoa

Congo

Benin

Algeria

Romania

Gibraltar

Cyprus

Turkey

Sweden

Portugal

Norway

Italy

Iceland

Greece

France

Denmark

Belgium

Australia
Libya

Ivory Coast

Gabon

Egypt

Cameroon

Angola

UK

Malta

Slovakia

Bulgaria

Switzerland

Spain

Poland

Netherland

Ireland

Hungary

Germany

Finland

Czech Republic

Austria

New Zealand 